\title{
High temperature low cycle fatigue
}

\author{
P RODRIGUEZ and S L MANNAN \\ Indira Gandhi Centre for Atomic Research, Kalpakkam 603 102, India
}

\begin{abstract}
Fatigue at high temperature is a complex phenomenon as it is influenced by a number of time-dependent processes which become important at elevated temperatures. These processes include creep, oxidation, phase instabilities and dynamic strain ageing (DSA), acting either independently or synergistically influence fatigue behaviour, often lowering the fatigue life. Current design approaches employ linear summation of fatigue and creep damage with suitable factors on permissible damage to take care of uncertainties in interaction between cyclic and time-dependent processes. It is, therefore, important to develop a deeper understanding of the processes that occur during high temperature fatigue so that realistic life predictions could be made.

Results on the high temperature fatigue behaviour of austenitic stainless steels, ferritic steels and nickel base alloys are presented here. The important mechanisms of interaction of high temperature time-dependent processes with fatigue under various conditions are discussed in detail. Emphasis is placed on cyclic stress response, fatigue life, deformation substructure and fracture behaviour. This is followed by a review of important life prediction techniques under combined creep-fatigue loading conditions. Life prediction techniques considered here include linear damage summation, strain range partitioning, ductility exhaustion approach, frequency modified and frequency separation methods, techniques based on hysteresis energy and damage rate models, and methods based on crack-cavitation interation models.
\end{abstract}

Keywords. Low cycle fatigue; creep-fatigue interaction; environmental effects; dynamic strain ageing; life prediction techniques.

\section{Introduction}

Low cycle fatigue (LCF) is an important design consideration in structural integrity analysis of components operating at high temperatures. Repeated thermal stresses are generated as a result of temperature gradients which occur on heating and cooling during start-up, shut-down and thermal transient conditions. LCF resulting from startups and shut-downs occurs under essentially strain-controlled conditions, since the surface region is constrained by the bulk of the component. Figure 1 shows schematically the stress and strain cycles to which a boiler or a steam turbine component may be 

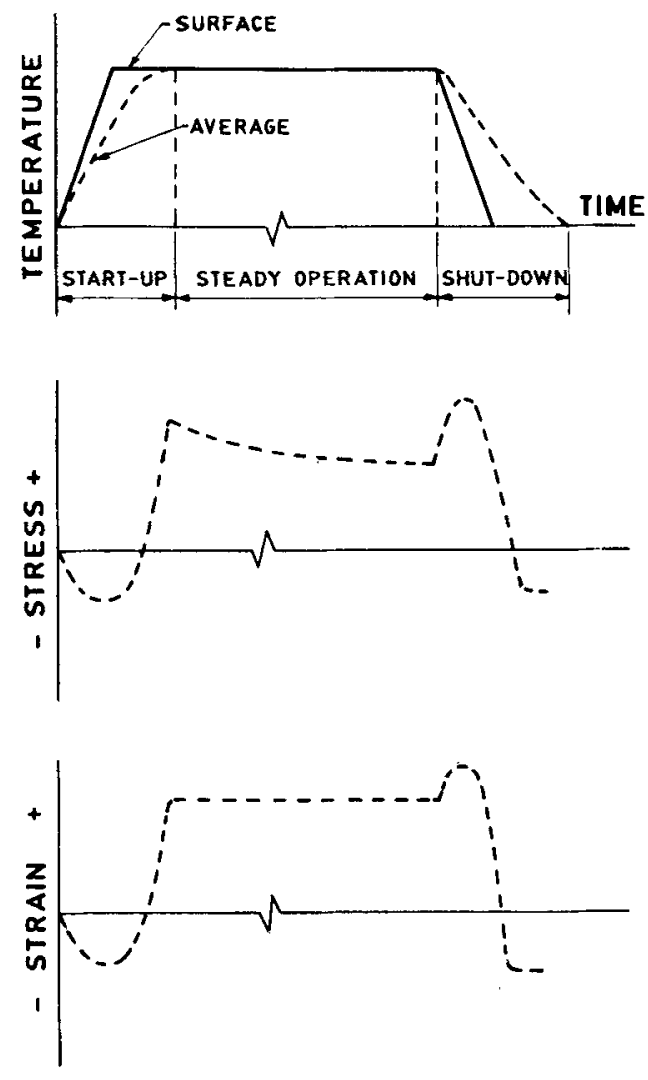

Figure 1. Schematic diagram illustrating thermal stresses/ strains to which boiler or steam turbine component may be subjected.

subjected to as a result of rapid start, steady state operation or a sudden shut-down. Typical temperature-time transients experienced by the surface of thick components in a fast reactor as a result of reactor trip (down shock) or secondary circuit failure (up shock) and the resulting stress--strain cycles are shown in figure 2.
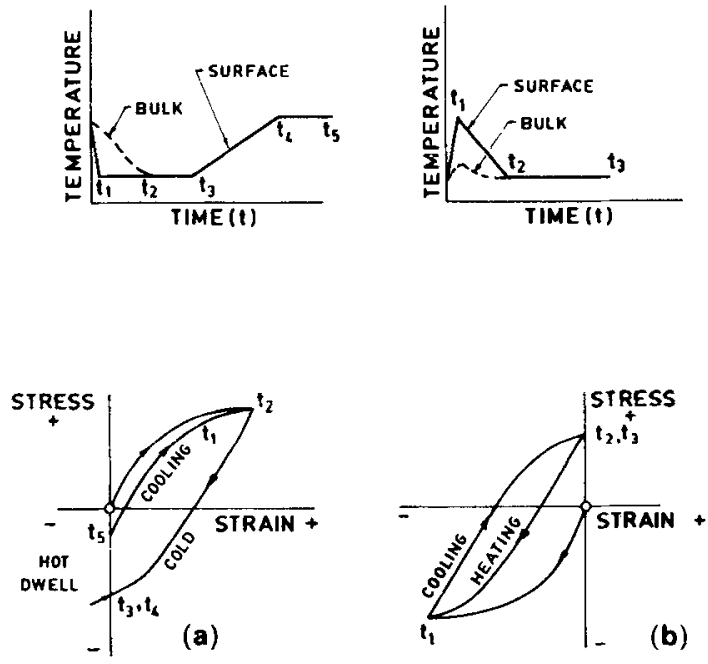

Figure 2. Surface hysteresis loops following reactor trip transient (a), heating transient (b), after secondary circuit failure in a fast breeder reactor. 
To represent the component behaviour in a laboratory test, the thermal strains are replaced by mechanical strains, introduced and controlled under isothermal conditions, figure 3. The slow start-up/shut-down cycle is replaced by a symmetrical and continuous fatigue cycle of equal strain rates in tension and compression with a hold period at a constant peak strain to simulate the on-load period i.e. creep-fatigue interaction (figures 3b-d). Slow-fast and fast-slow strain-time wave forms represent another category used to evaluate creep-fatigue interaction effects (figures $3 \mathrm{e}-\mathrm{f}$ ). In slow-fast cycle, tension-going strain rate is less than that in compression cycle, while in fast-slow cycle, compression-going strain rate is less than that in tension. Tension hold alone, compression hold alone, slow-fast and fast-slow wave forms are considered unbalanced cycles.
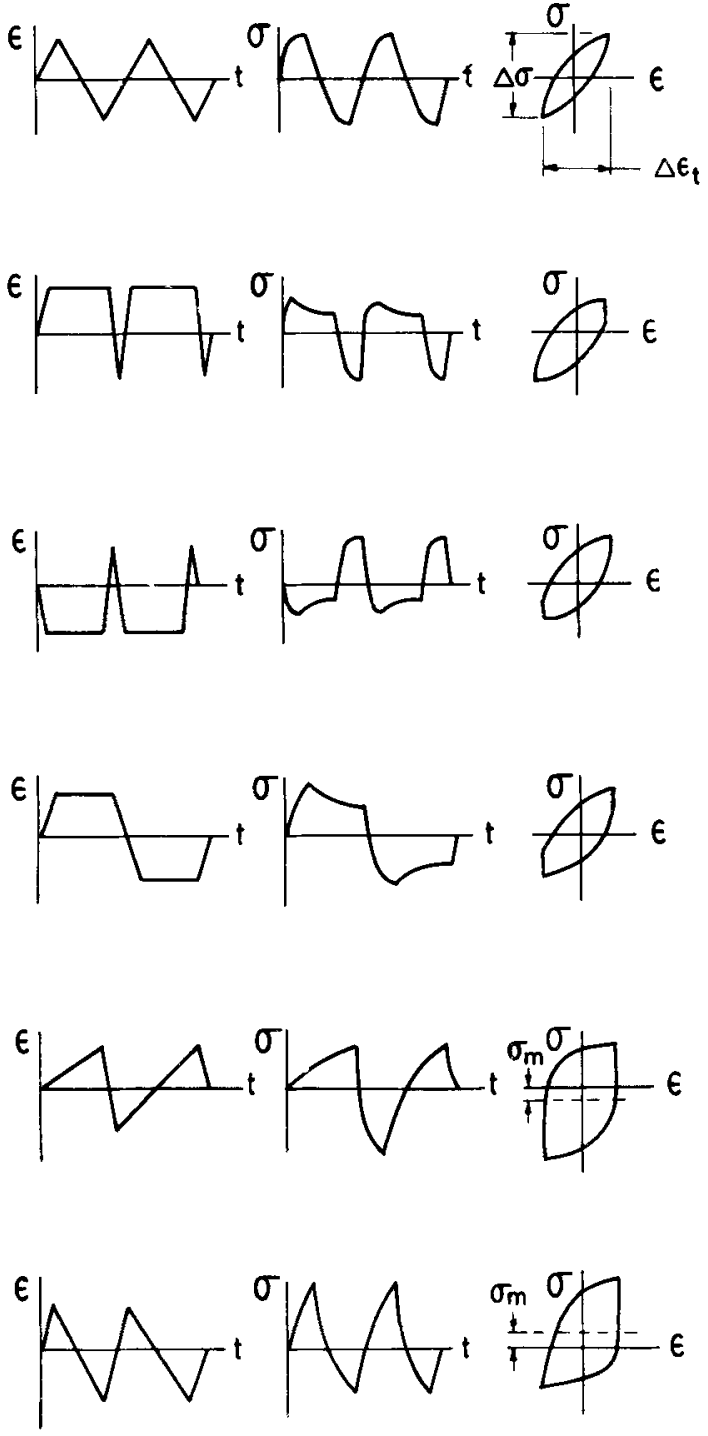

(a)

(b)

(c)

(d)

(e)

Figure 3. Typical waveforms employed in LCF testing. $\Delta \sigma=$ total stress range, $\Delta \varepsilon_{\mathrm{r}}=$ total strain range and $\sigma_{m}=$ mean stress. (a) Continuous strain cycling; (b) tension strain hold; (c) compression strain hold; (d) tension and compression strain hold; (e) slow-fast cycling; (f) fastslow cycling. 
LCF behaviour of materials at high temperatures and low test frequencies is influenced by the interaction of time-dependent processes like creep, oxidation, dynamic strain ageing (DSA) and metallurgical instabilities with cyclic deformation. In general, fatigue life decreases with increasing temperature and decreasing frequency. A few exceptions, however, have been reported as in the case of type 304 Stainless Steel (SS) (Bhanu Sankara Rao 1989), type 316 SS (Kanazawa \& Yoshida 1975) and $12 \% \mathrm{Cr}$ ferritic steel (Kanazawa 1978). In the case of type 304 SS (Bhanu Sankara Rao 1989), the observed increase in fatigue life with temperature correlated with the precipitation of $\mathrm{M}_{23} \mathrm{C}_{6}$ carbides during testing. Carbide precipitation along grain boundaries inhibits grain boundary sliding, thereby preventing grain boundary crack formation. Since LCF life at elevated temperature is governed by intergranular crack initiation and propagation, reduced tendency for grain boundary cracking due to precipitation leads to enhanced life with increasing temperature (Bhanu Sankara Rao 1989).

Elevated temperature fatigue tests conducted in air generally yield lower life than those carried out in vacuum, suggesting the deleterious effects of oxidation on fatigue properties (Coffin 1972a; Solomon \& Coffin 1973; Cook \& Skelton 1979). High temperature low cycle fatigue studies in ferritic steels such as $2.25 \mathrm{Cr}-1 \mathrm{Mo}$ (Sandhya et al 1989) and 9 Cr-1 Mo steels (Choudhary et al 1991a) indicate that oxidation enhances intergranular damage and consequently causes reduction in life. The effect of oxidation was more dominant in tests conducted at low strain amplitudes. Fatigueoxidation interaction has also been observed to degrade the life in austenitic stainless steels (Bhanu Sankara Rao et al 1986a). Creep-fatigue interaction behaviour of type 304 SS has been studied employing hold time tests (Bhanu Sankara Rao 1989). The results of this study indicate that tensile hold caused more damage to life than either compression hold or symmetrical (tension + compression) hold. Under tensile hold conditions, the accumulation of intergranular creep damage in the form of cavities enhanced the tendency for intergranular mode of fatigue crack propagation leading to shorter fatigue life. Degradation in life has been observed (Hirakawa et al 1978; Yamaguchi et al 1978) also under test conditions where creep and oxidation effects are expected to be minimal. It has been shown that another time-dependent process, namely, dynamic strain ageing interacts with fatigue and leads to life reduction.

In this paper, the role of environment, DSA and creep in determining the LCF behaviour will be first discussed. This is followed by a discussion on important techniques for life prediction under conditions of time-dependent fatigue. Empirical techniques as well as those with a mechanistic basis would be discussed.

\section{Environmental effects on fatigue behaviour}

One of the major factors responsible for the degradation of fatigue properties at elevated temperatures is the interaction of environment (oxygen or air) with fatigue process. In general, it is observed that materials exhibit superior fatigue properties in vacuum or in an inert medium compared to those observed in air (Coffin 1963, 1972, 1973, 1979; Asada \& Mitsuhashi 1980; Bressers \& Roth 1983; Marshall 1983; Jianting et al 1984). The influence of environment becomes more pronounced with lowering of frequency (strain rate), decreasing strain amplitude, and imposition of hold during fatigue testing. Depending on test frequency, three regimes of interaction of fatigue with environment could be identified (figure 4): (a) frequency independent regime (where 


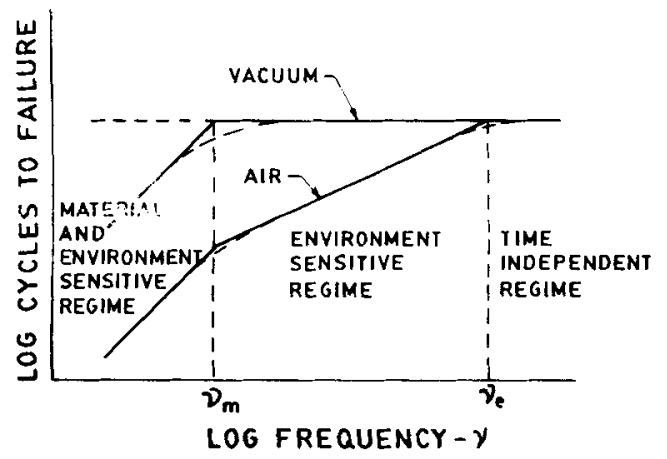

Figure 4. Effect of frequency on fatigue life at elevated temperatures (Coffin 1977).

time-dependent deformation mechanisms are not significant), (b) environment sensitive regime, and (c) deformation mode and environment interaction regime (Coffin 1977). At very high frequencies $\left(v>v_{e}\right)$, fatigue crack is open only for a short while, and therefore enough time is not available for environmental interaction. Crack growth in this regime is not dependent on environment. At lower frequencies $\left(v_{e}>v>v_{m}\right)$, environment influences the crack growth process and a change in the mode of crack growth from transgranular to intergranular takes place. At still lower frequencies $\left(v<v_{m}\right)$, the fracture mode is entirely intergranular and for a specific plastic strain range, time to failure remains constant (independent of frequency) (Coffin 1977).

A few experimental results would be considered to illustrate the role of environment in determining fatigue life. The effect of frequency and strain range on LCF behaviour of type 304 SS has been extensively investigated at elevated temperatures in air using balanced cycles (Bhanu Sankara Rao 1989). Decreasing frequency was found to degrade fatigue resistance of type 304 SS (figure 5) (Bhanu Sankara Rao 1989; Bhanu Sankara Rao et al 1991). No creep damage in the form of grain boundary cavities and cracks was noticed. It was also observed that as the frequency was lowered, crack initiation changed from slip band induced transgranular to oxidation induced intergranular mode (figure 6). The role of oxidation in determining fatigue life has been clearly brought out in comparative tests in air and vacuum environments on A286, figure 7 (Coffin 1972b). Fatigue life has been found to decrease with decrease in frequency in air environment while life is independent of frequency in vacuum.

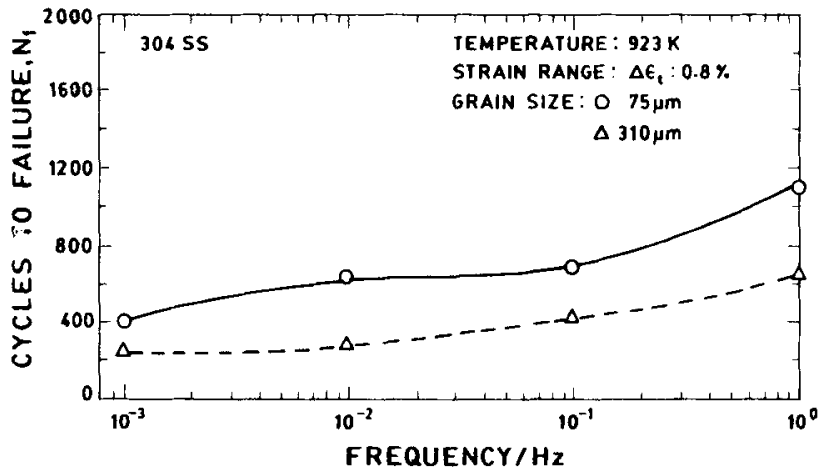

Figure 5. Influence of frequency on fatigue life as a function of grain size in 304 SS. 


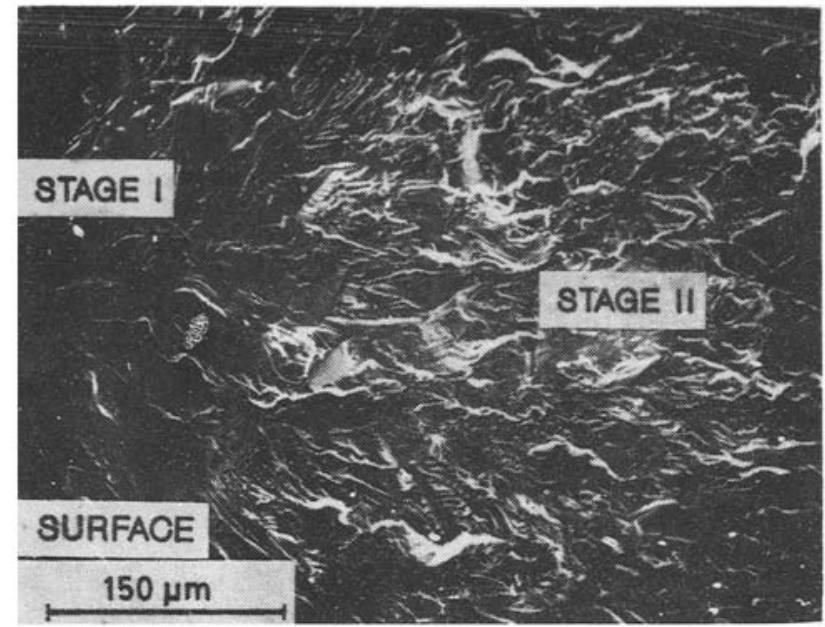

(a)

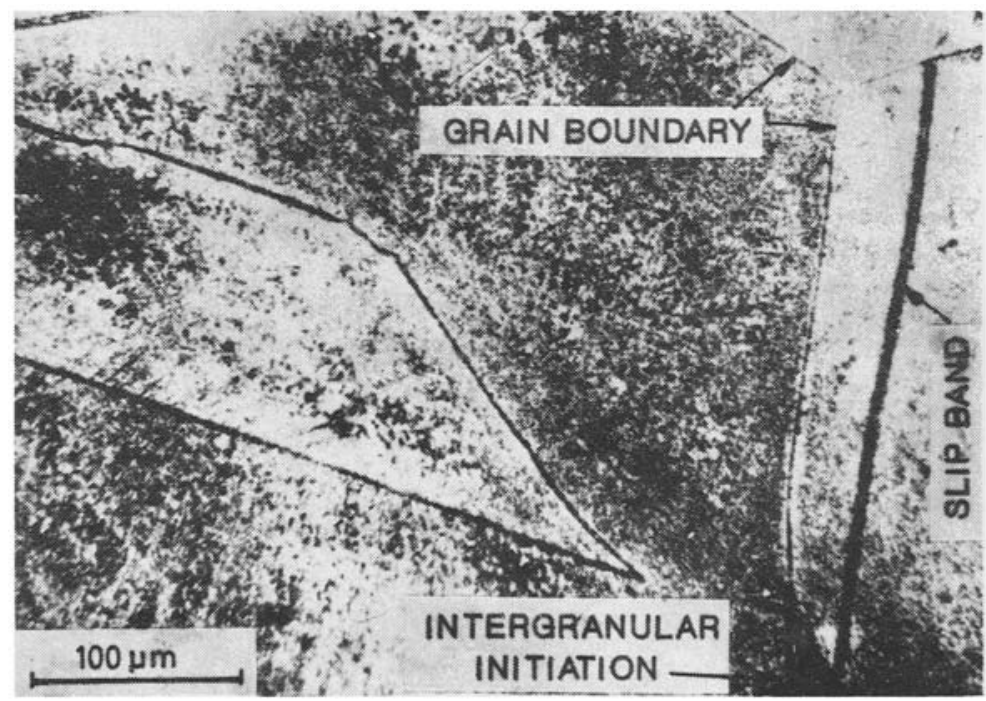

(b)

Figure 6. Crack initiation modes in type 304 SS LCF tested at $923 \mathrm{~K}$. (a) Transgranular crack initiation $\left(\Delta \varepsilon_{t}=0.66 \%, v=1.0 \mathrm{~Hz}\right)$ and (b) oxidation assisted transgranular crack initiation at $v=0.001 \mathrm{~Hz}$.

Strain amplitude also has significant influence in determining environmental effects. During low strain amplitude fatigue tests, material is exposed for longer durations to air environment at high temperatures. This provides sufficient time for oxidation to affect the failure process. A two-slope behaviour observed in a $2 \cdot 25 \mathrm{Cr}-1 \mathrm{Mo}$ steel has been attributed to the enhanced oxidation effects at low strain amplitudes, figure 8 (Sandhya et al 1989).

Enhanced environmental interaction has also been reported in hold time tests. For $2.25 \mathrm{Cr}-1 \mathrm{Mo}$ steel, compressive holds have been found to be more damaging than tensile holds (Teranishi \& McEvily 1980; Challenger et al 1981). This has been 


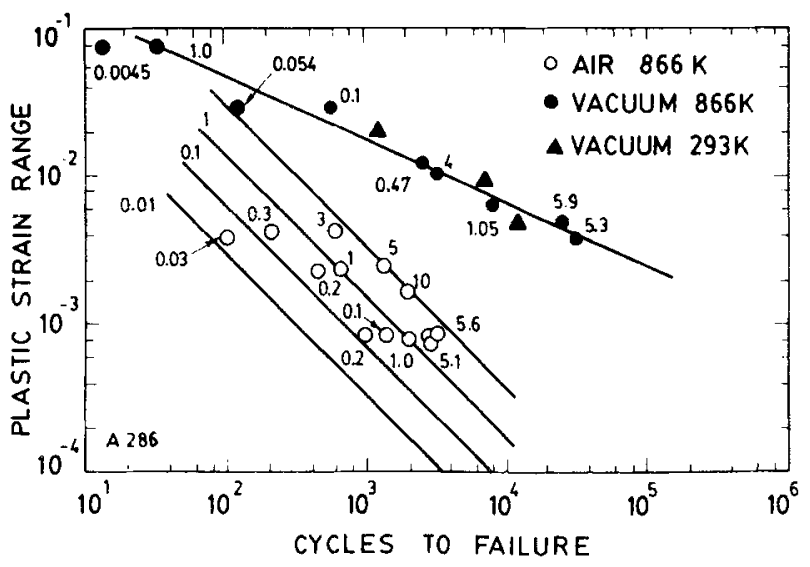

Figure 7. Plastic strain range vs fatigue life of A286 in air at $866 \mathrm{~K}$ and in vacuum at $293 \mathrm{~K}$ and $866 \mathrm{~K}$. Numbers adjacent to test points indicate frequency in cycles per minute (Coffin 1972b).

attributed to the behaviour of the oxide formed during hold period (Teranishi \& McEvily 1980). The oxide spalls from the specimen surface after a tension hold, leaving behind a relatively smooth surface. On the other hand, after a hold in compression, the oxide cracks, facilitating early crack nucleation in the underlying metal. This behaviour was later related to the tensile strain in the oxide by Challenger et al (1981). According to these authors, the loading waveform determines the tensile strain experienced by the oxide. Since the oxide formed during compression hold is subjected to a tensile strain equal to the total strain range of the test on a strain reversal, it is more likely to crack in a direction perpendicular to the applied stress. The vulnerability of superalloys to compressive dwell periods has also been interpreted in terms of environmental interaction on similar lines (Manson et al 1984). On the other hand, Sandhya et al (1989) have found tensile holds to be more damaging in normalized and tempered $2.25 \mathrm{Cr}-1 \mathrm{Mo}$ steel and have interpreted the results in terms of faster crack growth rates under tensile holds. Accelerated crack growth rates due to oxidation has been reported by various investigators (Smith et al 1969; Solomon \& Coffin 1973;

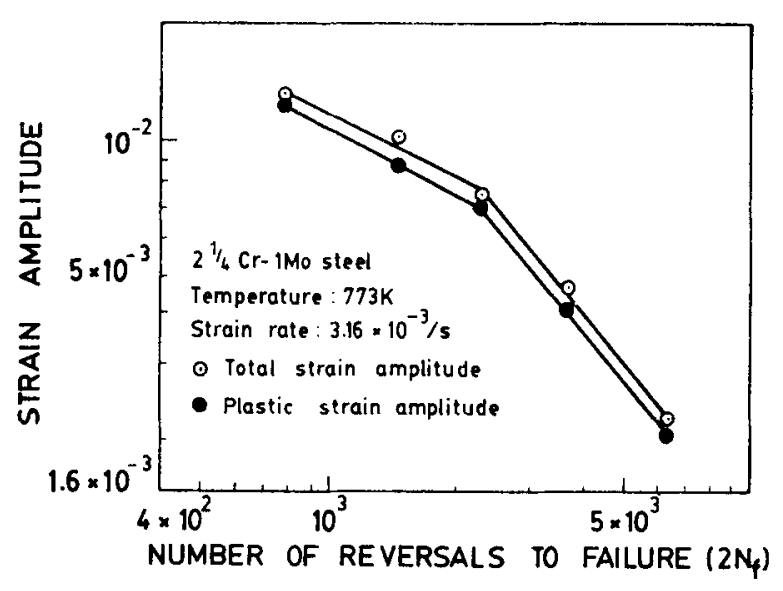

Figure 8. Coffin-Manson plots for $2 \cdot 25 \mathrm{Cr}-1$ Mo steel at $773 \mathrm{~K}$. 


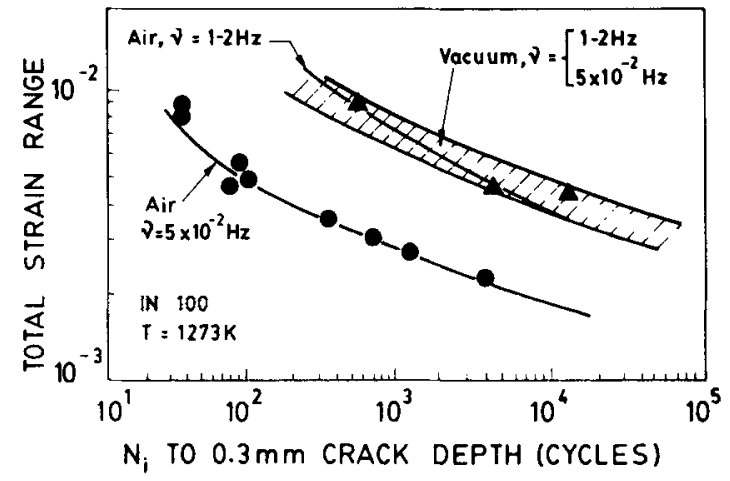

Figure 9. Oxidation induced frequency effect on the number of cycles spent in initiating a crack of $0.3 \mathrm{~mm}$ in IN 100 at 1273 K (Reger \& Remy 1986).

Frandson et al 1974; James \& Knecht 1975; Skelton 1978). Oxidation accelerates fatigue crack initiation, and generally leads to increased number density of microcracks, figure 9 (Bressers et al 1983; Reger \& Remy 1986). The large reduction in number of cycles for crack initiation is often associated with a change in the mode of cracking from transgranular to intergranular. The transition in the mode of fatigue crack initiation in a gamma-prime strengthened PM Astroloy and in a carbide and solid solution strengthened alloy $800 \mathrm{H}$ are compared in figure 10 (Bressers 1985). PM Astroloy when tested in vacuum shows a transition from transgranular to intergranular mode of crack initiation at a temperature much higher compared to that in air, whereas for alloy $800 \mathrm{H}$, the change in transition temperature was very small. The trans- to intergranular transition in the PM Astroloy has been attributed to environmental effects while in Alloy $800 \mathrm{H}$, it has been shown to be creep controlled.

The effect of frequency on fatigue crack propagation rate has been studied by Solomon \& Coffin (1973) for A286, at 866 K, and Scarlin (1977) on Nimonic 105 at $1023 \mathrm{~K}$ and IN738 LC at $1123 \mathrm{~K}$. In the investigation on A286 (Solomon \& Coffin 1973), it is found that, in air at very high frequencies crack propagation is due to frequency independent fatigue, with transgranular fracture (figure 11). However, as frequency decreases the environmental effects interact with the fatigue process thereby increasing crack growth rate. At still lower frequencies, the influence of other timedependent processes such as creep becomes dominant resulting in intergranular

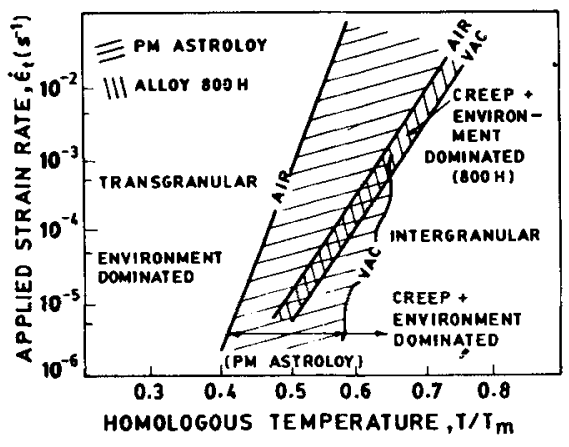

Figure 10. Transition in the mode of crack initiation of PM Astroloy and of Alloy $800 \mathrm{H}$ as a function of the applied strain rate and temperature in air and in vacuum (Bressers 1985). 


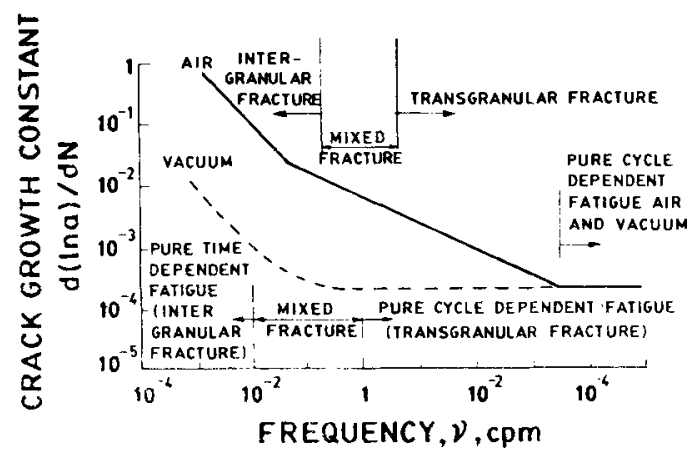

Figure 11. Effect of frequency and environment on low cycle fatigue crack propagation of A286 at $866 \mathrm{~K}$ (Solomon \& Coffin 1973).

fracture. The dependence of crack growth on frequency sets in at a lower frequency in vacuum compared to air.

It must be pointed out that oxidation is not always detrimental to fatigue (Gell \& Leverant 1973). Oxidation strengthening has been reported in Mar-M200 alloy and attributed to increased crack tip radius and blunting of the crack by oxidation. Further, corrosion products at the crack tip can cause closure during unloading which decreases the effective stress intensity range and thus retard cracking (Floreen \& Raj 1985).

Damage from oxidation is viewed as a synergistic phenomenon when plastic deformation or fracture occurs at a free surface or at an exposed crack tip. Brittle protective oxide films formed are ruptured exposing fresh nascent material and chemical attack of the material then proceeds until newly formed protective films intervene. With fatigue, this process of straining, film rupture and attack occurs repeatedly, leading to localization of the cyclic strain and an abundance of reaction products (McMahon \& Coffin 1970; Sidey \& Coffin 1979). Various mechanisms have been suggested to account for the effect of environment on fatigue life (Cook \& Skelton 1979; Duquette 1979; Ericsson 1979). At temperatures below and test frequencies above the range of intergranular cracking, the effect of oxidation on stage I cracking in planar slip alloys has been explained on the basis of slip step passivation mechanism reducing the degree of slip reversibility and thus enhancing crack nucleation at slip steps (Fujita 1958). Alternatively, cyclically generated slip bands may concentrate oxygen through strain-induced vacancy generation, thus accelerating transition from slip band to microcrack by preventing the rewelding of nascent cracks (Thompson et al 1955). It has also been suggested that crack nucleation is speeded up as a result of dislocation accumulation against surface oxide films, leading to cavity formation on the slip band (Shen et al 1966). The preferential oxidation of second phases which intersect the surface, such as carbides in nickel base alloys has also been invoked to rationalise fast crack initiation (Coffin 1973b; Reuchet \& Remy 1983). In the intergranular failure regime, faster crack initiation is related to the existence of an easier path for chemical reaction. Inward diffusion of oxygen and its interaction with segregated elements or carbides present on the grain boundary can produce gaseous species, which may facilitate nucleation of cavities (Bricknell \& Woodford 1981: Nich \& Nix 1981; Dyson 1982; Taplin et al 1983). Oxygen could promote cavitation by lowering the surface energy and thereby decreasing the threshold stress for cavity nucleation (Yoo \& Trinkaus 1983) or by enabling the reduction in the critical radius of cavity for growth (Taplin et al 1984). 


\section{Dynamic strain ageing}

DSA arises due to the interactions between solute atoms and mobile dislocations during plastic deformation. Its characteristics in tensile deformation have been reviewed in detail by several investigators (Mannan 1981; Rodriguez 1984; Abdel-Azim Metwally 1986; Venkadesan 1991). Important manifestations of DSA in tensile deformation include serrations on stress-strain curves, peak/plateau in flow stress variation with temperature, negative strain rate sensitivity of flow stress, and increased work hardening rate and decrease in tensile ductility with increasing temperature or decreasing strain rate. Serrations occur on the stress-strain curve after the material has been deformed to a critical strain $\varepsilon_{c}$. The value of $\varepsilon_{c}$ depends on test temperature, strain rate and material condition. The characteristics of different types of serrations and the experimental conditions that produce them have been discussed in detail by Rodriguez (1984). Various models have been proposed to explain the phenomenon of DSA and observed characteristics in tensile deformation (Cottrell 1953; Sleeswyk 1958; McCormick 1972; Mulford \& Kocks 1979; Van den Beukel \& Kocks 1982; Hayes \& Hayes 1984; Kubin \& Estrin 1990).

\subsection{Effect of DSA on LCF}

Even though DSA has been investigated in detail in tensile deformation, its role in influencing LCF has been examined to a limited extent (Conway 1968; Bressers \& Verhegghee 1981; Bhanu Sankara Rao 1989; Bhanu Sankara Rao et al 1990, 1991; Srinivasan et al 1991; Valsan et al 1994) and recently Mannan (1993) has reviewed this subject. The improtant manifestations of DSA in LCF include serrated flow in plastic portion of the stress-strain hysteresis loop (figure 12), a rapid strain hardening (figure 13), an increase in stress response with decreasing strain rate (negative strain rate sensitivity) or increasing temperature, and a minimum in the plastic strain component of the cycle at half life (Bhanu Sankara Rao et al 1990, 1991; Srinivasan et al

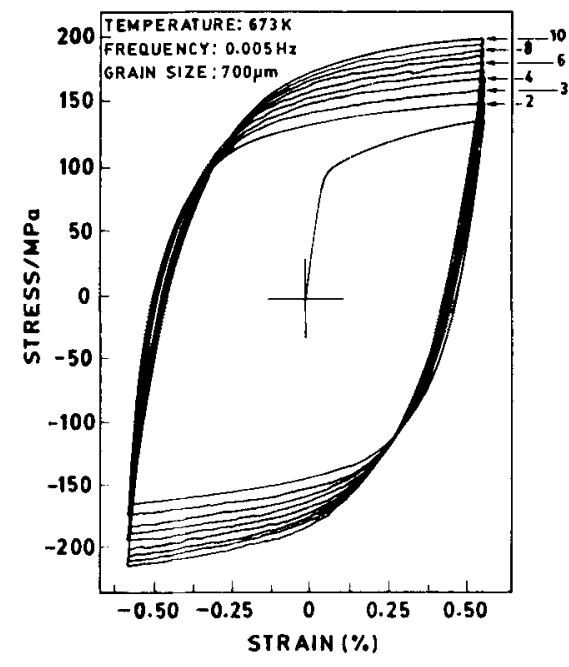

Figure 12. Stress-strain hysteresis loops exhibiting serrated flow in LCF test conducted at $673 \mathrm{~K} \mathrm{(304SS;}$ grain size: $700 \mu \mathrm{m}$; strain range: $1.2 \%$ ). 


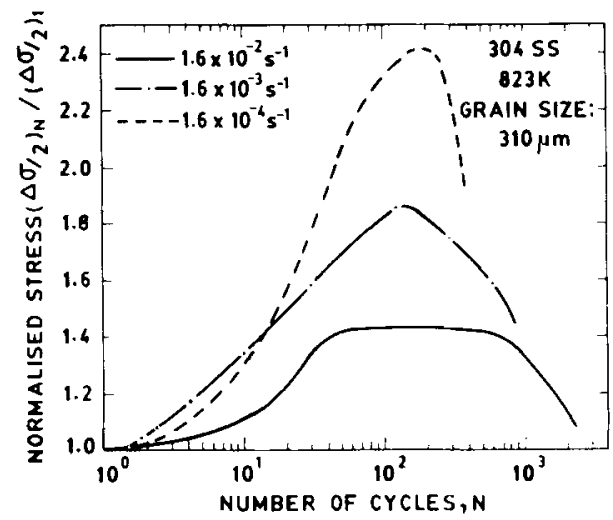

Figure 13. Normalized cyclic hardening curves illustrating the influence of strain rate at $823 \mathrm{~K}$ for type $304 \mathrm{SS}$ (GS: $310 \mu \mathrm{m}$; strain amplitude: $\pm 0 \cdot 4 \%$.

1991; Valsan et al 1994). Figure 13 shows the influence of strain rate on the normalized peak stress $\left((\Delta \sigma / 2) /(\Delta \sigma / 2)_{1}\right)$ for a type $304 \mathrm{SS}$ at $823 \mathrm{~K}$. When strain rate is decreased from $1.6 \times 10^{-2}$ to $1.6 \times 10^{-4} \mathrm{~s}^{-1}$ there is an increase in the cyclic stress response. Another example of the influence of DSA on cyclic stress response is shown in figure 14, which shows the results on Nimonic PE-16 alloy at $823 \mathrm{~K}$ over strain rates varying from $3 \times 10^{-5} \mathrm{~s}^{-1}$ to $3 \times 10^{-2} \mathrm{~s}^{-1}$ (Valsan et al 1994). The negative strain rate sensitivity of cyclic stress response is clearly seen in this figure.

A comparison of LCF and tensile deformation (Bhanu Sankara Rao et al 1990) indicates that serrated flow occurs over a wider temperature range in LCF than in tensile deformation. Onset of serrations in LCF occurs at a lower temperature compared to that in monotonic deformation. This is attributed to the enhanced diffusion of solute atoms with the aid of non-equilibrium vacancies generated during fatigue cycling. Reverse straining generates vacancies at a rate greater than unidirectional deformation (Johnson \& Johnson 1965; Essman \& Mughrabi 1979; Quesnel \& Tsou 1983; Bhanu Sankara Rao et al 1986b).

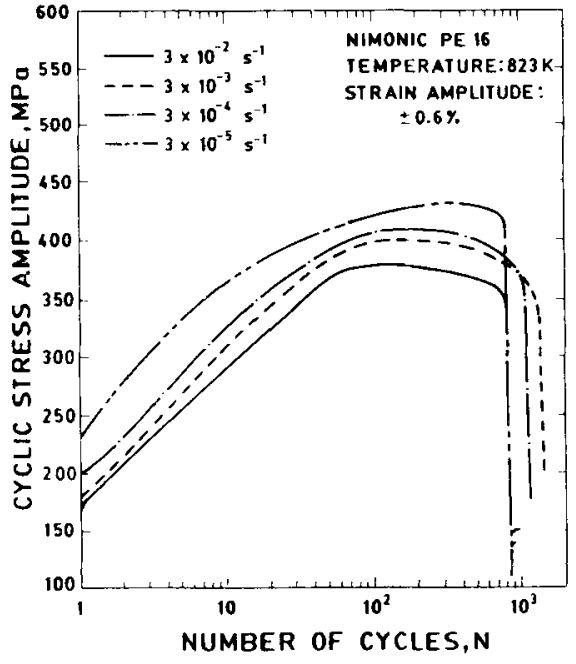

Figure 14. Cyclic stress response of Nimonic PE16 as a function of strain rate at $823 \mathrm{~K}$. 
The occurrence of DSA during cyclic deformation influences dislocation substructure. In type 310SS (Kanazawa et al 1988) the substructure changes from cells at temperatures below $473 \mathrm{~K}$ to a planar arrangement at temperatures between 473-823 K (DSA range) and back to cell/subgrains structure beyond $823 \mathrm{~K}$. In the DSA regime, the formation of cells/subgrains is retarded by locking of dislocations by solute atoms thereby restricting cross slip and climb processes. Detailed studies carried out in the authors' laboratory on $316 \mathrm{LN}$ SS over a temperature range 298-873 K have clearly confirmed the transition from cells to planar slip bands in the temperature range $573-873 \mathrm{~K}$, where DSA effects are predominant (Srinivasan et al 1991), figure 15. Further, studies conducted on $304 \mathrm{SS}$ at $823 \mathrm{~K}$ over the strain rate range $1.6 \times 10^{-2}$ to $1.6 \times 10^{-4} \mathrm{~s}^{-1}$ (Bhanu Sankara Rao et al 1991) showed an increase in the slip planarity with decrease in strain rate. Typical intense planar slip bands developed in the alloy at $1.6 \times 10^{-4} \mathrm{~s}^{-1}$ are shown in figure 16. It may be noticed that there is a uniform distribution of dislocations in the interband region. It has been suggested that DSA enhances the degree of inhomogeneity of deformation during LCF by solute locking of slow moving dislocations between slip bands. Presumably, dislocation velocities inside the slip bands are too high for dynamic ageing of mobile dislocations to take place and consequently DSA enhances the partitioning of cyclic strains into separate regions marked by high and low amplitudes of dislocation movement (Wilson \& Tromans 1970; Abdel-Raouf et al 1973; Bhanu Sankara Rao et al 1989; Valsan et al 1994).

DSA during LCF has been found to localize deformation. Figure 17 shows the variation of slip band spacing ' $i$ ' with strain rate in PE-16 alloy (Valsan et al 1994). The increase in ' $i$ ' at lower strain rates and higher temperatures is attributed to enhanced DSA effects. Intergranular cracking due to impingement of slip bands has been observed in many alloys (Tsuzaki et al 1983; Bhanu Sankara Rao et al 1988; Bhanu Sankara Rao 1989; Valsan et al 1994) under conditions of dynamic strain ageing.

It must be pointed out that planar slip generally enhances slip reversibility and hence resistance to both transgranular crack initiation and propagation (Valsan 1991; Valsan et al 1992). However, if stress concentrations associated with dislocation pile-ups cause intergranular cracks, or localized deformation in widely spaced slip bands causes transgranular cleavage cracks, then development of slip planarity will reduce fatigue life. Fracture mode has been found to be influenced under DSA conditions in LCF. SEM studies on type 304 SS (Bhanu Sankara Rao et al 1990) revealed that at the two higher strain rates $\left(1.6 \times 10^{-3} \mathrm{~s}^{-1}\right.$ and $\left.1.6 \times 10^{-2} \mathrm{~s}^{-1}\right)$ fatigue crack propagated transgranularly by ductile striation mechanism, and by a mixed transgranular and intergranular mode at the lowest strain rate $\left(1.6 \times 10^{-4} \mathrm{~s}^{-1}\right)$, figure 18. It should be noted that the occurrence of serrated flow coincided with the development of intergranular cracking. Also, where negative strain rate sensitivity existed but no serrated flow occurred, crack propagation remained transgranular. Intergranular decohesion at $\dot{\varepsilon}=1.6 \times 10^{-4} \mathrm{~s}^{-1}$ (figure 18c), was caused by the impingement of slip bands on grain boundaries. Further, the higher stress response developed during strain controlled LCF in the DSA range (figures 13 and 14) would lead to a large stress concentration at the crack tip and increased crack growth rates (Bhanu Sankara Rao 1989; Valsan et al 1994). Moreover, higher response stresses would act to reduce the critical crack size for final fracture thus reducing cyclic life (Bressers \& Verhegghee 1981). 


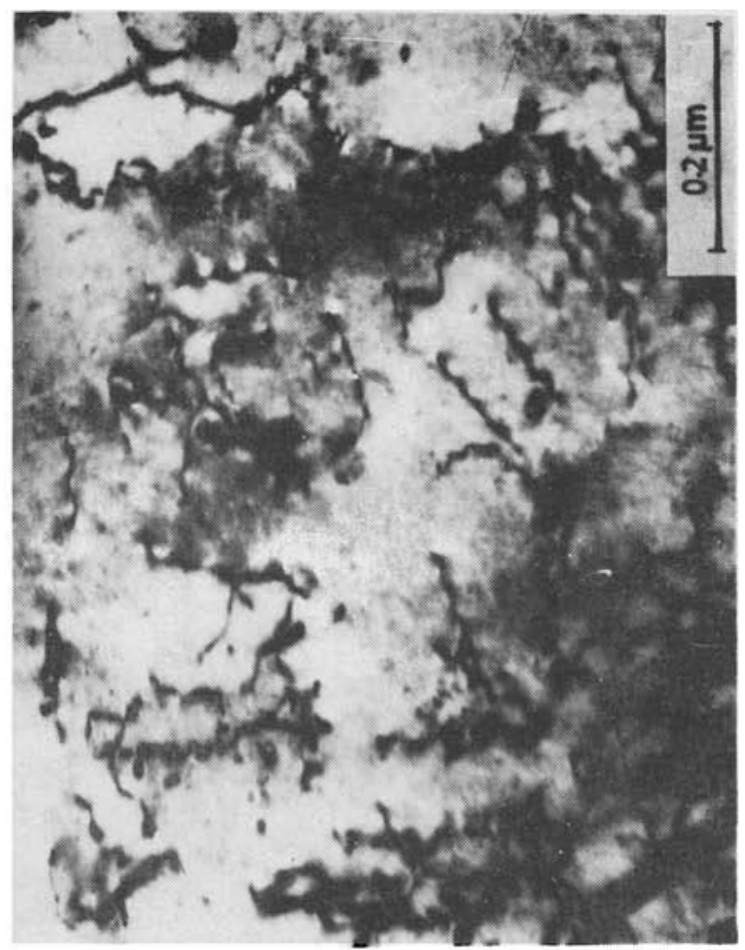

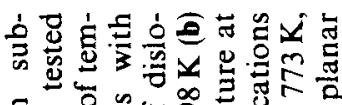

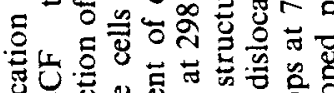

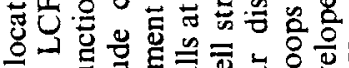

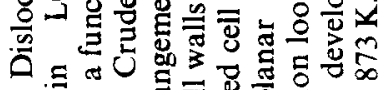

ฐ

ம்

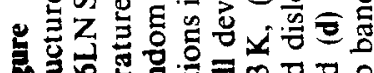

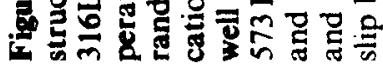

ङ

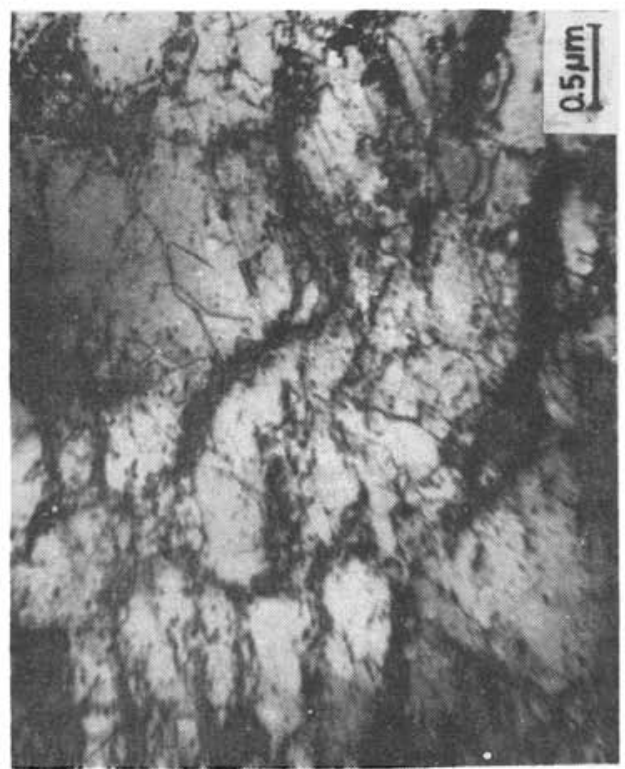

ఏ

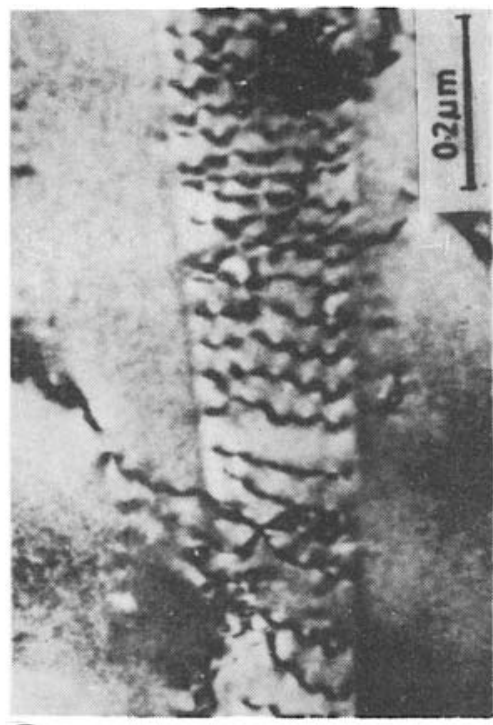

무

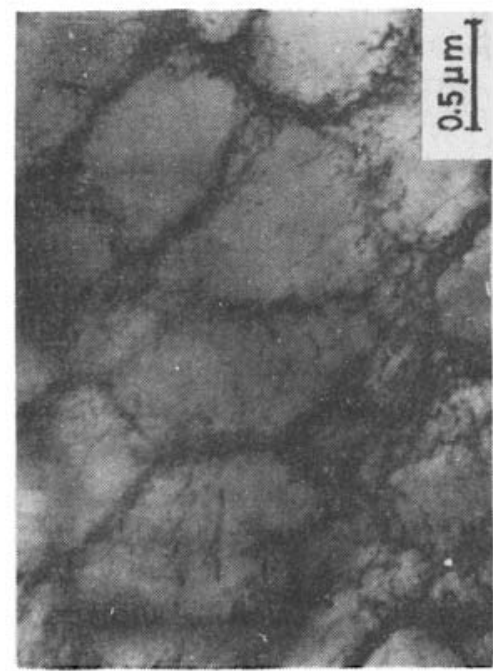

อ 


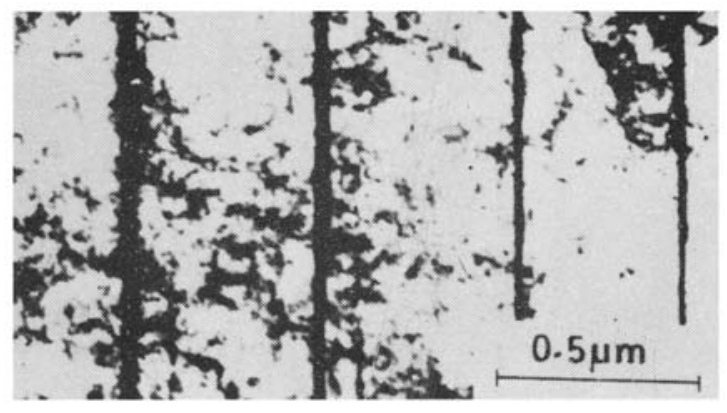

Figure 16. Slip bands and uniform distribution of dislocations in the interband regions (304 SS, grain size: $310 \mu \mathrm{m}$, $\dot{\varepsilon}=1.6 \times 10^{-4} \mathrm{~s}^{-1}$ ).

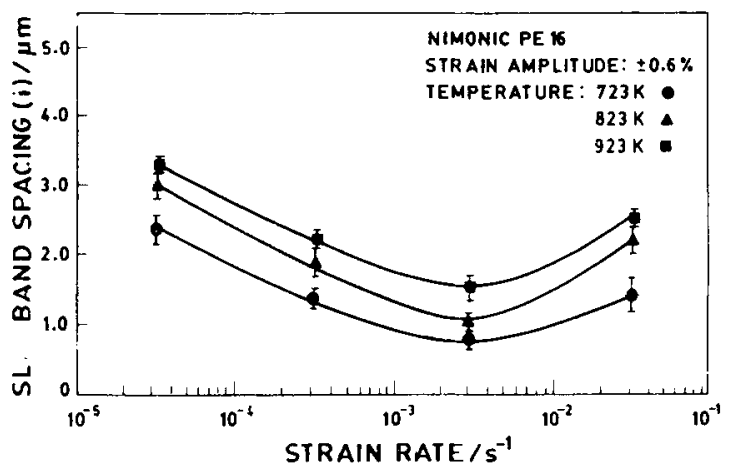

Figure 17. Variation of average slip band spacing ' $i$ ' with strain rate in Nimonic PE16.

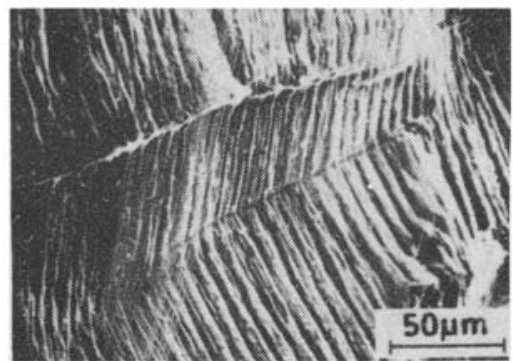

(a)

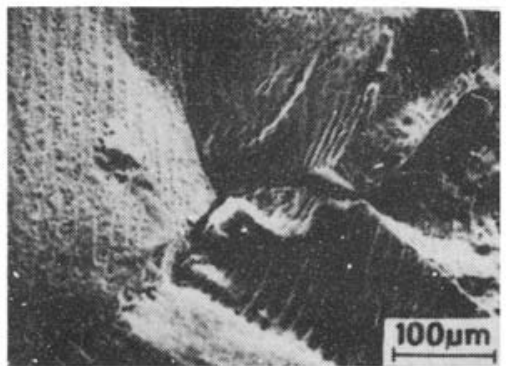

(c)

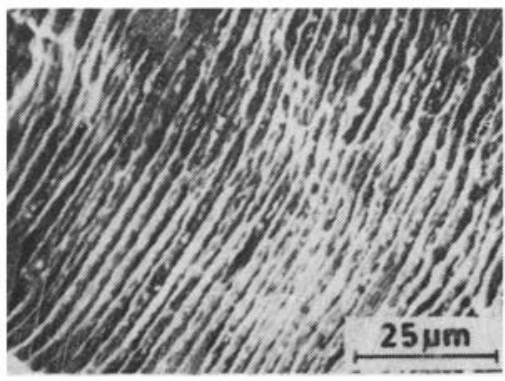

Figure 18. Crack propagation modes as a function of strain rate at $823 \mathrm{~K}$ in type $304 \mathrm{SS}$. (a) Transgranular stage II propagation $\left(\dot{\varepsilon}=1.6 \times 10^{-2} \mathrm{~s}^{-1}\right)(\mathrm{b})$ transgranular stage II propagation $\left(\dot{\varepsilon}=1.6 \times 10^{-3} \mathrm{~s}^{-1}\right)$ and $(\mathbf{c})$ mixed mode propagation $\left(\dot{\varepsilon}=1.6 \times 10^{-4} \mathrm{~s}^{-1}\right)$. 


\section{Creep-fatigue interaction}

Creep-fatigue interaction refers to the situation in which the rate of damage accumulation under complex loading differs from linear summation of damage rates produced by creep component and cyclic component. This subject has recently been reviewed by Rodriguez \& Bhanu Sankara Rao (1993). Creep-fatigue interaction studies are generally carried out by introducing a component of creep into normal fatigue cycle (figure 3). This can be done by means of constant strain tensile (or compressive) dwell (figures $3 b-d$ ) or by reducing the tensile (or compressive) strain rate in the cycle (figures $3 \mathrm{e}$ and $\mathrm{f}$ ). As the creep component of the cycle is increased by increasing the tensile dwell period or by reducing the tensile strain rate, failure mode also changes. The failure modes observed can be categorized into three distinct regimes:

(1) fatigue dominated,

(2) fatigue-creep interaction, and

(3) creep dominated.

These three types of failure modes are shown in figure 19. Fatigue dominated failure arises due to growth of surface fatigue cracks through the specimen, with no evidence of interaction with creep damage (figure 19a). During fatigue-creep interaction, creep cavitation damage is found within the material in addition to surface fatigue damage. Fatigue and creep damages initially develop independently and the likelihood of true interaction depends on the balance between them. In tensile hold time tests on $316 \mathrm{SS}$ at elevated temperatures, it is found that initial fatigue crack growth rates are similar to those occurring under continuous cycling conditions as demonstrated by fatigue striation measurements (Wareing 1977). However, eventually the fatigue crack interacts with creep damage, resulting in accelerated crack growth, a reduction in endurance and creep-fatigue interaction failure (figure 19b). When such interaction occurs, the failure path would become mixed (trans-plus intergranular). Finally, under certain testing conditions, the creep component of the cycle dominates and intergranular fracture due to the accumulation of grain boundary cavitation results (figure 19c); under these conditions there is no interaction with fatigue damage.

To understand creep-fatigue interaction let us first consider microstructural characteristics of creep failure and fatigue failure. Creep failure is caused by cavitation damage
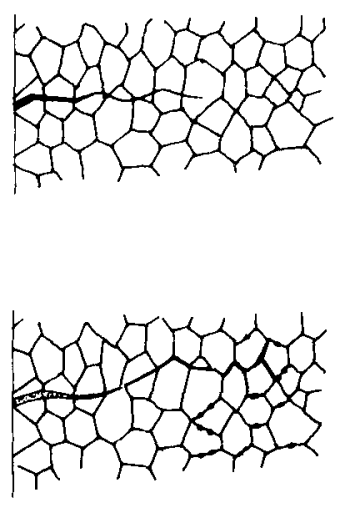

a)

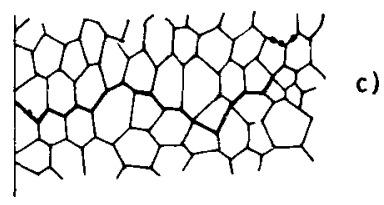

Figure 19. Schematic diagram

b) of failure modes during creepfatigue interaction testing. (a) Fatigue dominated, (b) fatiguecreep interaction, and (c) creep dominated. 
while fatigue failure occurs by crack damage. The creep-fatigue failure can then be viewed from two points:

(1) influence of cyclic loading on cavitation damage,

(2) influence of cavitation on crack initiation and propagation.

Creep-fatigue failure can be dominated by either cavitation-damage or by crackdamage. Conceptual mechanisms for each of these have been proposed by Raj (1985). These are illustrated in figures 20 and 21. In the case of cavitation damage, the imposition of cyclic loading enhances the rate of damage formation (figure 20). It can be seen that the integrated stress-time area is smaller for cyclic loading than it is for monotonic loading, yet cavitation damage is greater. Influence of cavitation damage on fatigue crack initiation and propagation is illustrated in figure 21 . Here cavitation may enhance either crack initiation or propagation. Experimental evidence indicates that in pure fatigue, only one or two cracks are initiated, whereas, in creep-fatigue many grain boundaries at the surface develop cracks, and the largest among them propagates as the major crack. In the case of cavitation enhanced crack propagation, cracks can grow by lengths much greater than crack tip opening displacement due to the linkage of cavities ahead of the crack tip. Tomkins \& Wareing (1977), Wareing et al (1980) and Rie et al (1988) have analysed the problem of fatigue crack growth in the presence of grain boundary cavitation and have suggested that fast crack growth rates occur when the following condition is satisfied.

$$
\delta / 2=\lambda-p,
$$

where, $\delta$ is the crack tip opening displacement, and $p$ and $\lambda$ are average cavity size and spacing respectively.

Extensive creep-fatigue interaction tests conducted on several high temperature alloys have shown that addition of tensile dwell periods dramatically reduces life compared to continuous cycling (Berling \& Conway 1970; Brinkman et al 1972; Conway et al 1975; Wareing 1975, 1977, 1981; Maiya \& Majumdar 1977; Schmitt et al

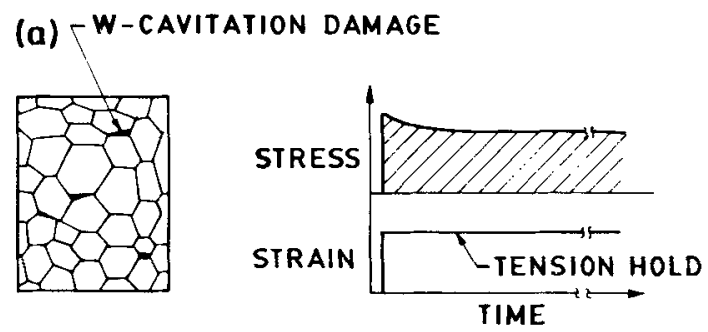

(b)

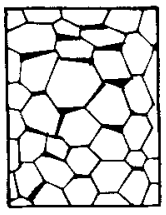

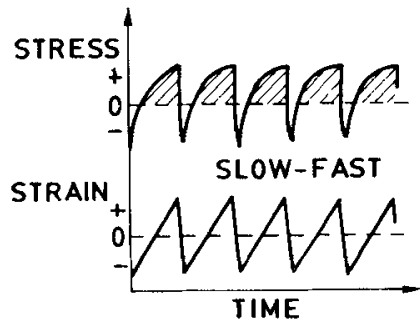

Figure 20. In a cavitation dominated failure, cyclic loading enhances the rate of damage accumulation. For example the integrated stress time area is smaller for cyclic loading (b), than it is for monotonic loading (a), yet the damage is greater for cyclic loading (Raj 1985). 

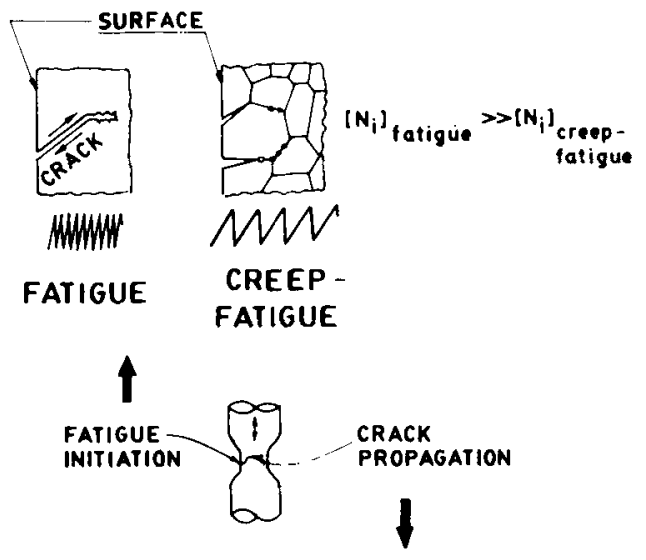
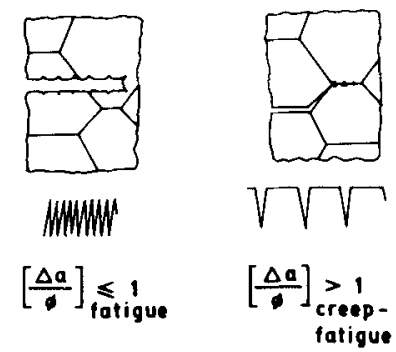

Figure 21. In crack dominated failure, cavitation can accelerate either crack initiation or crack propagation. $\left(N_{i}=\right.$ cycles for crack initiation $\Delta a / \phi=$ (crack advance per cycle)/(crack tip opening displacement) (Raj 1985).

1979; Brinkman 1985; Meurer et al 1984; Bhanu Sankara Rao et al 1986a, 1993). Balancing tensile dwell with compressive dwell has been shown to enhance the life time compared to dwell in tension alone (figure 22)(Ellison \& Patterson 1976). This has been attributed to reduced intergranular creep damage due to introduction of compression dwell. On the other hand, endurance of $9 \mathrm{Cr}-1 \mathrm{Mo}$ steel has not been found to be influenced by the introduction of tensile dwell (Wood et al 1979; Choudhary et al 1991a). This material is characterized by a high creep ductility and no evidence of intergranular cracking is found in the tensile dwell period tests. These results suggest that creep ductility is a very important parameter in influencing endurance in hold time tests. Figure 23 shows data for several ferritic steels (Miller et al 1984). It is evident that, lower the ductility, the lower is the fatigue-creep endurance. In addition, it is clear that long dwell periods, small strain ranges and low ductility favour creep dominated failures, whereas, intermediate strain ranges, short dwell periods and high creep ductility favour fatigue-creep interaction failures.

Extensive tests on austenitic alloys have revealed that influence of hold time on fatigue lives depends not only on ramp rate, position and length of the hold, but also on microstructure (Maiya \& Majumdar 1977; Wareing 1981; Bhanu Sankara Rao 1989; Bhanu Sankara Rao et al 1993). Figure 24 illustrates the combined influence of tensile strain holds, ramp strain rate and temperature on the endurance of 304 SS (Schmitt et al 1979). There is a reduction in life as dwell period is increased at elevated temperature; however at temperatures below $823 \mathrm{~K}$, hold period does not seem to have any significant influence. Apart from the accumulation of damage during the hold period, a substantial part of the damage is generated during loading and unloading periods as well (figure 24). 


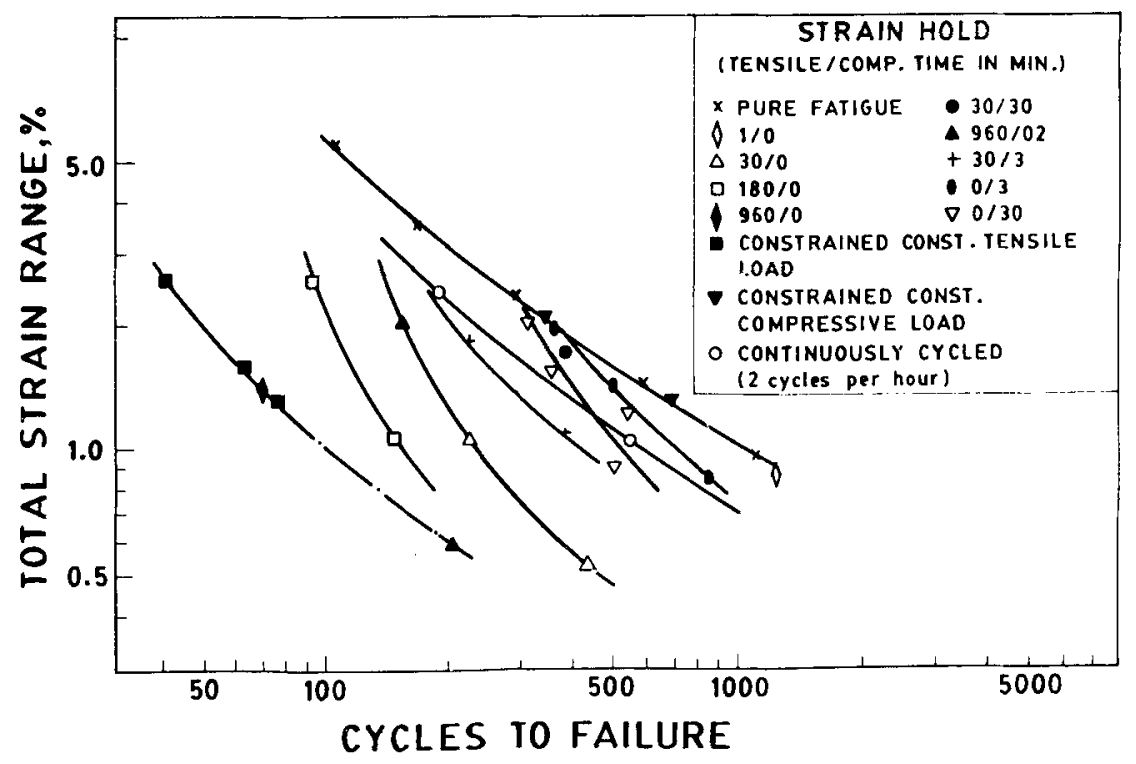

Figure 22. Plot of total strain range vs. cycles to failure for $1 \mathrm{CrMoV}$ steel at $838 \mathrm{~K}$ (Ellison \& Patterson 1976).

Creep-fatigue interaction behaviour of 304 SS base metal and 308 weld metal have been recently investigated by Bhanu Sankara Rao et al (1993). These tests were conducted at $923 \mathrm{~K}$ employing a total strain range of $1.0 \%$ and hold period of 1 minute in tension, compression and in both tension and compression. Fatigue life of weld metal

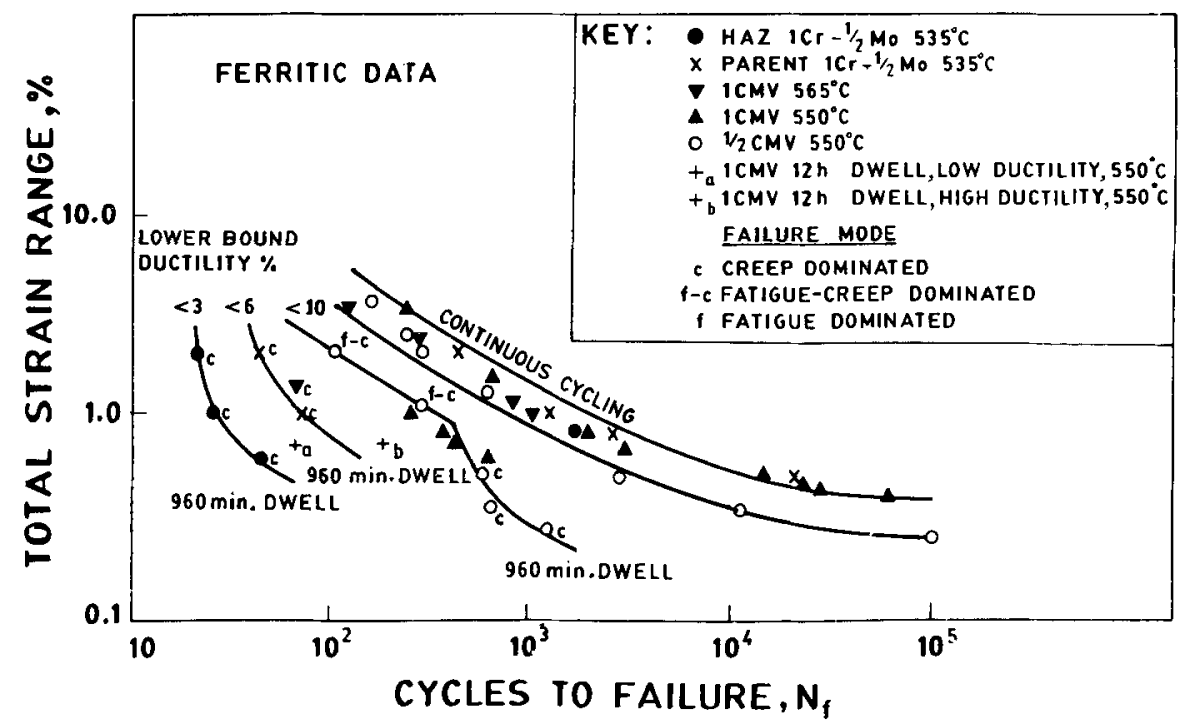

Figure 23. Effect of ductility on endurance and fracture mode in low alloy ferritic steels (Miller et al 1984). 

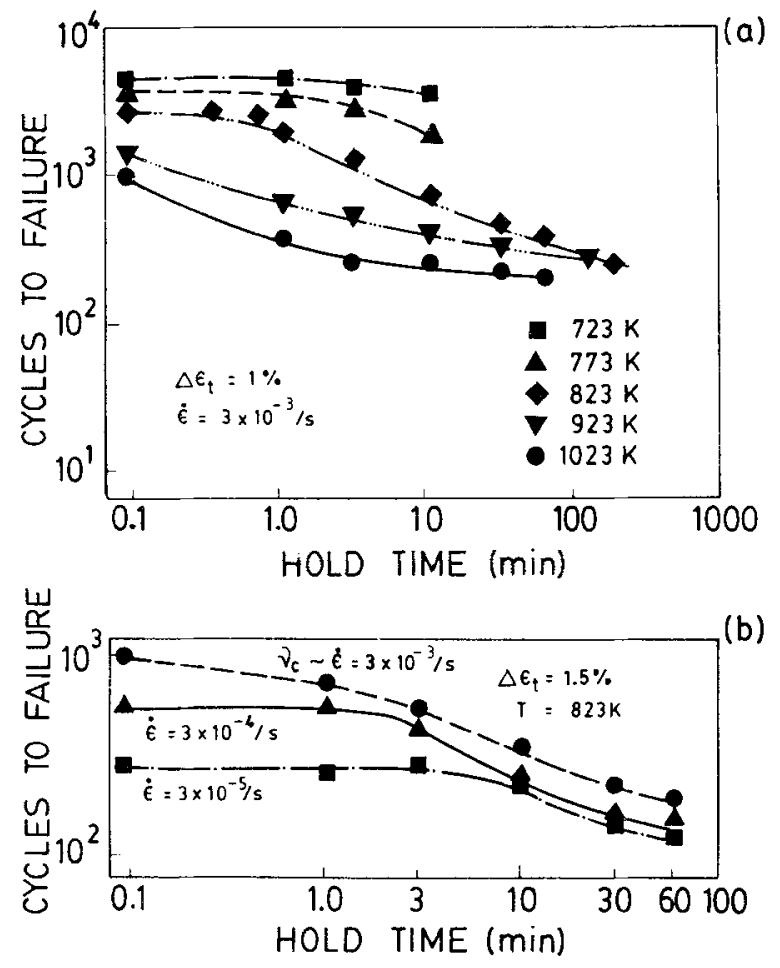

Figure 24. The influence of tensile hold duration on fatigue life of type 304 SS (a) for different temperatures, (b) for different strain rates (Schmitt et al 1979).

was inferior to base metal (Brinkman et al 1974; Bhanu Sankara Rao et al 1993). Effect of hold period on life was dependent not only on the material condition and duration of hold, but also on the position of the hold in the cycle. 304 SS reveals a severe degradation in life with a tension hold compared with continuous cycling. Compression hold lowered life marginally while for hold both in tension and compression, life values in between those for hold in tension alone and compression alone were observed. Mean stress was not found to be the reason for the observed differences in the behaviour. Fractographic investigations revealed bulk creep damage in tests with tension hold periods (figure 25a) while fracture modes associated with compression holds and continuous cycling were characterized by ductile striations (figures $25 \mathrm{~b}$ and c).

In nickel base alloys, compressive strain holds have been found to be more detrimental than tensile hold (Wells \& Sullivan 1969; Lord \& Coffin 1973; Ostergren 1976a; Antunes \& Hancock 1978). Development of tensile mean stress (Plumbridge \& Ellison 1987), differences in the shapes of cavities formed during tension and compression (Wells \& Sullivan 1969) and load shedding effects due to multiplicity of cracks in tensile dwell (Nazmy 1983a, 1983b) have been suggested as possible reasons for observed damaging effects of compression hold.

Creep-fatigue interaction has also been investigated employing slow-fast and fast-slow types of waveforms (figures $3 \mathrm{e}$ and $\mathrm{f}$ ). Generally maximum fatigue endurance has been observed in fast - fast cycling and minimum in slow-fast (Majumdar \& Maiya 1979; Bhanu Sankara Rao et al 1986c, 1988; Kempf et al 1987). Factors which contribute to the observed differences in the failure modes and fatigue lives in these tests have been recently discussed by Rodriguez \& Bhanu Sankara Rao (1993). Development 

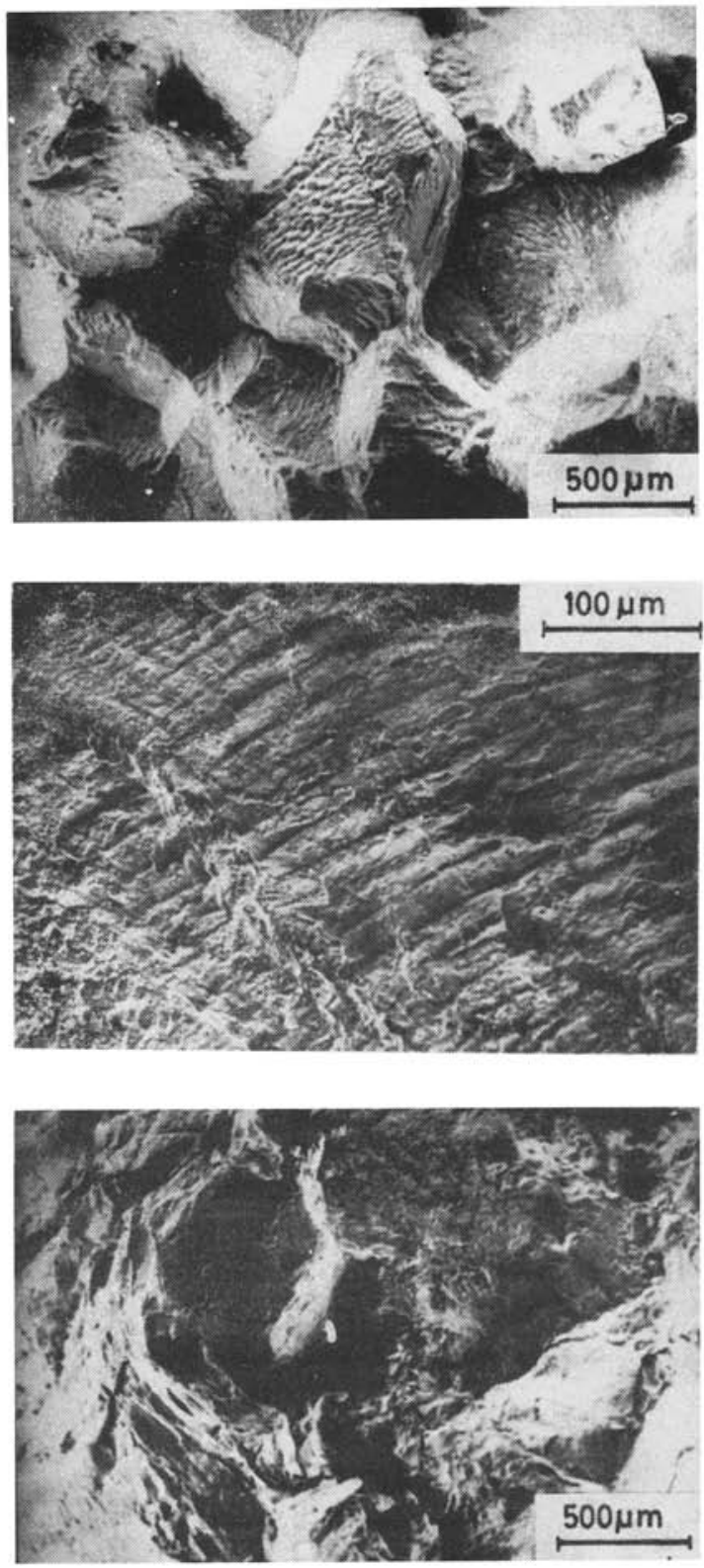

(a)

(b)

(c) Figure 25. Crack propagation in $1 \mathrm{~min}$ hold time tests on $304 \mathrm{SS}$ at $923 \mathrm{~K}$. (a) Tension hold: intergranular propagation; (b) compression hold: transgranular propagation; and (c) tension plus compression hold: mixed mode propagation.

of cavitation damage due to slow strain rates is considered to be responsible for reduced fatigue lives.

Actual components in high temperature plants are subjected to complex cyclic loading situations where creep-fatigue interaction plays a dominant role. An in-depth knowledge of high temperature fatigue behaviour is necessary for design as well as life assessment and remnant life estimation of structural components. Various life predic- 
tion methods applicable to high temperature fatigue condition have been proposed and these are reviewed in the following section.

\section{Life prediction methods for high temperature low cycle fatigue}

Several life prediction methods have been developed to assess fatigue life of the components under time-dependent fatigue conditions, and these include:

(1) prediction based on monotonic tensile properties;

(2) damage summation method;

(3) frequency modified and frequency separation methods;

(4) strain range and strain energy partitioning methods;

(5) hysteresis energy method;

(6) ductility exhaustion approach;

(7) damage rate model;

(8) Tomkins and Wareing's model; and

(9) Cavitation model by Rie et al (1988).

Detailed reviews of most of the models mentioned above are available in the literature (Lloyd \& Wareing 1981; Miller et al 1984; Rodriguez et al 1989; Viswanathan 1989; Rodriguez 1993; Rodriguez \& Bhanu Sankara Rao 1993). Marriott (1992) has recently reviewed the current trends in high temperature design rules covering creep and fatigue conditions. In the following section, the salient features of various life prediction methods are discussed.

\subsection{Method of universal slopes and $10_{\%}^{\circ}$ rule}

This method has been formulated to predict fatigue life from strength and ductility parameters derived from short time tension tests. The fatigue life is given as the summation of the elastic strain amplitude, $\Delta \varepsilon_{e} / 2$ (Basquin 1910), and the plastic strain amplitude, $\Delta \varepsilon_{p} / 2$ (Coffin 1954; Manson 1954) given by:

$$
\begin{aligned}
& \Delta \varepsilon_{e} / 2=\left(\sigma_{f}^{\prime} / E\right)\left(2 N_{f}\right)^{-\gamma}, \\
& \Delta \varepsilon_{p} / 2=\left(\varepsilon_{f}^{\prime}\right)\left(2 N_{f}\right)^{-\beta},
\end{aligned}
$$

where, $\sigma_{f}^{\prime}=$ fatigue strength coefficent, $E=$ elastic modulus, $\gamma=$ fatigue strength exponent, $\varepsilon_{f}^{\prime}=$ fatigue ductility coefficient, $\beta=$ fatigue ductility exponent and $N_{f}=$ number of cycles to failure. Based on the results on a variety of materials, Manson (1965) has suggested that the exponents and coefficients of these relationships can be universalised and proposed a generalized form for the strain-life relationship (universal slopes equation),

$$
\Delta \varepsilon_{t}=3 \cdot 5\left(\sigma_{u} / E\right) N_{f}^{-0.12}+D^{0.6} N_{f}^{-0.6}
$$

where, $\sigma_{u}=$ ultimate tensile strength, $D=$ ductility $=\ln (100 /(100-\% R A)), R A=$ reduction in area and $N_{f}=$ number of cycles to failure.

The deterioration in fatigue life at high temperatures aided by intergranular crack initiation and propagation has been empirically accounted for, in $10 \%$ rule (Manson \& Halford 1968) by factoring the fatigue life obtained from universal slopes equation by 10 . 
Further, a creep modified 10\% rule has been proposed (Manson \& Halford 1967) to evaluate fatigue life under those situations where the creep effects decrease fatigue life by more than a factor of 10 .

Universal slopes method and its modifications are useful in the early stages of design when fatigue properties of a material of interest may not have been measured yet. However, these methods cannot adequately account for the deterioration in fatigue life by creep and other time-dependent processes at high temperatures.

\subsection{Linear damage summation - time and cycle fraction rule}

This approach involves the linear summation of time and cycle fractions, wherein time fractions are used as a measure of creep damage (Robinson 1952) and cycle fractions are used as a measure of fatigue damage (Miner 1945). Failure in a creep-fatigue situation is expressed as,

$$
n / N_{f}+t / t_{r}=1
$$

where, $n=$ number of cycles at a strain range, $N_{f}=$ pure fatigue endurance at the same strain range, $t=$ time at a given stress and $t_{r}=$ time to rupture at the stress under pure monotonic loading.

The ASME design criterion (1992) based on this summation rule proposes a limit for allowable damage $D$. Further, $N_{f}$ and $t_{r}$ are replaced by $N_{d}$ and $T_{d}$ respectively

$$
\sum_{j=1}^{p}\left(n / N_{d}\right)_{j}+\sum_{k=1}^{q}\left(t / T_{d}\right)_{k} \leq D,
$$

where $D=$ total allowable creep-fatigue damage value, $n=$ number of cycles of loading condition $j, N_{d}=$ number of design-allowable cycles of loading condition $j, t=$ time duration of load condition $k$ and $T_{d}=$ allowable time at a given stress intensity. The values for $D$ are different for different materials. $D$ is unity for Alloy $800 \mathrm{H}$ but is in the range 0.6 to 1.0 for types 304 and 316 stainless steels (ASME Code Case N47 1992).

A creep-fatigue interaction diagram based on linear damage summation approach developed in our laboratory for $9 \mathrm{Cr}-1$ Mo steel thick section forging (Choudhary et al $1991 \mathrm{~b}$ ) is provided in figure 26a. This figure also incorporates thin section data from Wood et al (1979). Figure 26b gives creep-fatigue interaction diagram for $2 \cdot 25 \mathrm{Cr}-1 \mathrm{Mo}$ (Valsan et al 1988) based on the data available in literature (Booker \& Majumdar 1982; Swindeman \& Strizak 1982). It may be seen that for $9 \mathrm{Cr}-1$ Mo steel the data points lie above the $D=1$ line, while for $2.25 \mathrm{Cr}-1$ Mo steel damage values less than unity are needed for encompassing the test data.

The damage summation method is extensively employed in design codes in view of its simplicity as it requires only $\mathbf{S}-\mathrm{N}$ curves and stress rupture curves for life prediction. However, this approach has the following limitation:

(1) The value of damage $D$ is specific for each material.

(2) Tensile and compressive hold periods are considered equally damaging. In practice, compression holds are found to have a healing effect in austenitic steel (Bhanu Sankara Rao et al 1993, 1994) but in nickel-base superalloys they are more detrimental than tension holds (Wells \& Sullivan 1969; Antunes \& Hanrock 1978).

(3) The strain rate dependence of creep damage accumulation is not incorporated in this model. 

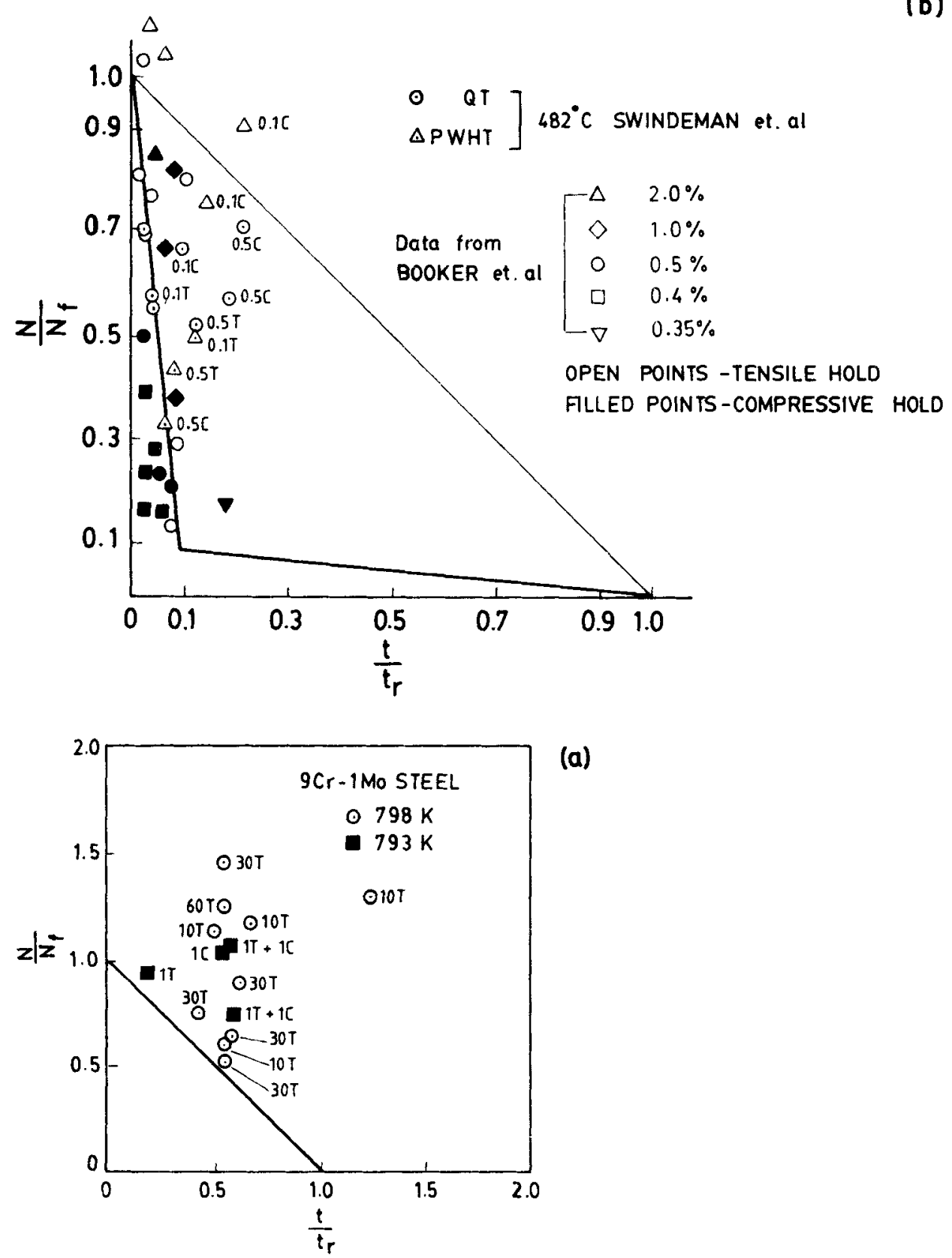

(a)

O-DATA FROM WOOD et al m-MDD DATA NUMBERS REPRESENT HOLD TIME IN MINUTES Figure 26. Linear damage $T$ - TENSION C-COMPRESSION

$T \cdot C$ - TENSION COMPRESSION summation diagram for (a) $9 \mathrm{Cr}-1 \mathrm{Mo}$ steel and (b) $2 \cdot 25 \mathrm{Cr}-$ 1 Mo steel.

(4) Stress rupture properties are determined from virgin material, whereas materials cyclically harden/soften depending on the alloy composition, metallurgical and testing conditions. 
(5) This method assumes a load path independence for fatigue and creep damages.

\subsection{Frequency modified and frequency separation methods}

This approach is essentially a modification of the Coffin-Manson relationship for pure fatigue (Coffin 1969, 1971, 1976, 1977). The time parameter is introduced to account for the environmental and other time-dependent factors, by incorporating a frequency term as follows:

$$
\Delta \varepsilon_{p}=A_{1}\left(N_{f} v^{k-1}\right)^{-\beta},
$$

where $A_{1}, k$ and $\beta$ are temperature-dependent constants. $k$ is a material parameter derived from the Eckel relationship (1951)

$$
v^{k} t_{f}=\text { constant }=f\left(\Delta \varepsilon_{p}\right),
$$

and $N_{f} v^{k-1}$ is the frequency modified life. Similarly, Basquin relationship is modified and summed to provide a relationship of total strain range.

$$
\Delta \varepsilon_{\mathrm{t}}=A_{1}\left(N_{f} v^{k-1}\right)^{-\beta}+A_{2} N_{f}^{-\beta} v^{k_{1}},
$$

where $A_{2}, \beta^{\prime}$ and $k_{1}^{\prime}$ are material and temperature-dependent constants. For treating hold time effects, the frequency is calculated from $v=1 /\left(t+t_{h}\right)$, where $t$ is the time for strain reversal and $t_{h}$ is the hold time in each cycle.

The concept of total cycle time does not adequately predict the fatigue behaviour for complex wave shapes. The effects of wave shape on damage are associated with tension going time and hysteresis loop imbalance. Frequency separation equation can be written as:

$$
N_{f}=\left(A_{1} / \Delta \varepsilon_{p}^{\prime}\right)^{1 / \beta}\left(v_{t} / 2\right)^{1-k}
$$

where $\Delta \varepsilon_{p}^{\prime}$ represents the loop imbalance (Coffin 19.77) and the term $(v, 2)^{1-k}$. accounts for the time spent in the tension part of the cycle. $\Delta \varepsilon_{p}^{\prime}$ is the equivalent plastic strain defined as:

$$
\begin{aligned}
\Delta \varepsilon_{p}^{\prime} & =\Delta \varepsilon_{p}\left[\left(\left(v_{c}^{\prime} / v_{l}\right)^{k_{1}}+1\right) / 2\right]^{\beta / \beta} \\
k_{1} & =k_{1}^{\prime}+\beta^{\prime}(k-1)
\end{aligned}
$$

where $v_{t}=$ tension-going frequency, $v_{c}=$ compression-going frequency, and $\beta^{\prime}$ and $k_{1}^{\prime}$ are the appropriate constants derived from the Basquin law. The frequency separation method has been found to give a good correlation between the experimental and the predicted lives for a variety of wave shapes and dwell times. figure 27 (Coffin 1977).

Advantages of frequency based approaches:

(1) Total strain is a major correlating parameter and hence is of direct use to designers.

(2) Subdivision of inelastic strains into various components is not made as in strain range partitioning method. Here the inelastic strain arising from a host of deformation processes is considered to be inseparable.

(3) Implicit in the method is an assumption that significant damage for a cycle occurs near the peak tensile strain and is affected by strain rate in reaching this maximum. 


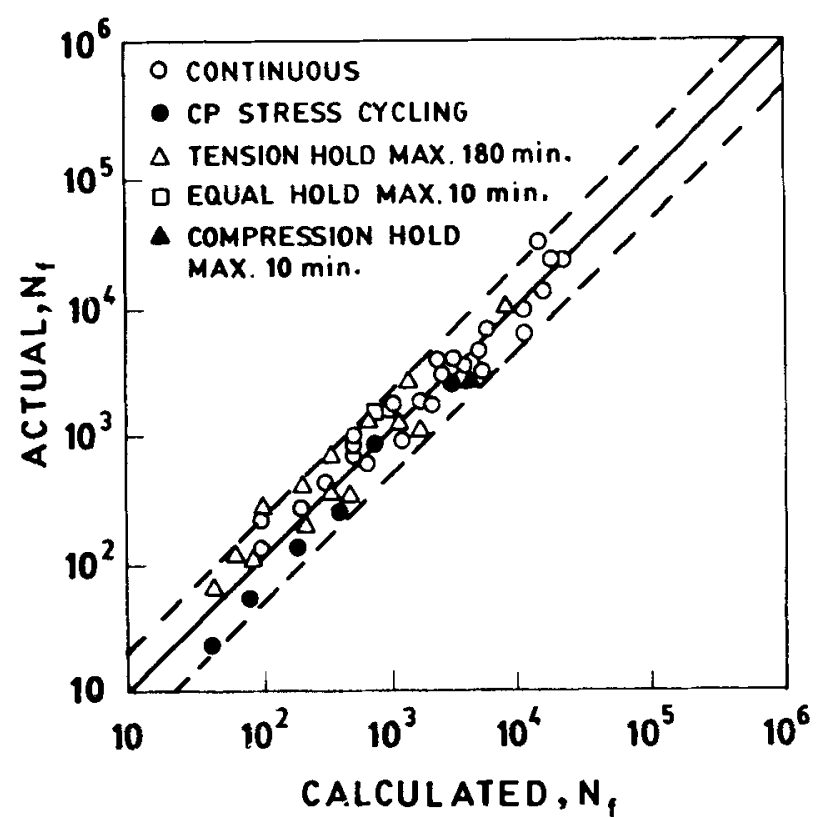

Figure 27. Fatigue life prediction for various heats of type $304 \mathrm{SS}$ at $867 \mathrm{~K}$ by frequency separation method (Coffin 1977).

Disadvantages:

(1) It is implied that the fatigue life decreases continuously with decrease in frequency. However, in certain materials homogenization of deformation (Valsan et al 1994) and thermal ageing cause improvement in fatigue life (Bhanu Sankara Rao 1989).

(2) No distinction is made between tension and compression dwell periods and to their damaging effects which are material dependent.

(3) Variable temperature effects are not accounted for.

(4) Analysis assumes that hysteresis loop is closed. Hence it cannot take care of strain ratchetting.

(5) Evaluation of the equation needs determination of several parameters.

(6) For complex loops, determination of frequency is difficult.

\subsection{Strain range partitioning approach}

In strain range partitioning (SRP) method (Manson et al 1971), the total inelastic strain range is partitioned into four possible components depending on the directions of straining (tension or compression) and the type of inelastic strain (creep or timeindependent plasticity), figure 28 (Hirschberg \& Halford 1976):

$\Delta \varepsilon_{p p}$ : tensile plastic strain reversed by compressive plastic strain:

$\Delta \varepsilon_{C P}$ : tensile creep strain reversed by compressive plastic strain;

$\Delta \varepsilon_{P C}$ : tensile plastic strain reversed by compressive creep strain;

$\Delta \varepsilon_{C C}$ : tensile creep strain reversed by compressive creep strain.

Partitioning of a generalized hysteresis loop is illustrated in figure 29 (Hirschberg $\&$ Halford 1976). Only three of these four generic strain ranges can exist in a given 
(a)

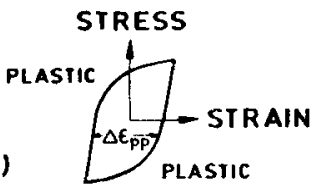

(c)

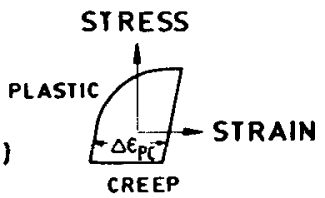

STRESS

(b)

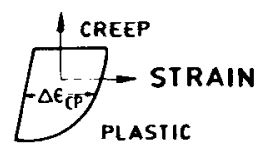

(d)

STRESS

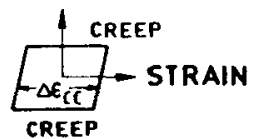

Figure 28. Idealised hysteresis loops for defining individual partitioned strain range-life relationships (a) $P P$, (b) $C P$, (c) $P C$ and (d) CC type of cycles (Hirschberg \& Halford 1976).

hysteresis loop. $\Delta \varepsilon_{P C}$ and $\Delta \varepsilon_{C P}$ cannot co-exist. By choosing suitable experiments, relations between inelastic strains and life, can be determined for a material of interest for each of these strain ranges:

$$
N_{j k}=A_{j k} \Delta \varepsilon_{j k}^{\beta_{j k}},
$$

where $j$ and $k$ represent plasticity or creep (Manson et al 1971; Hirschberg \& Halford 1976). The damage fractions resulting from each of the partitioned strain range components are summed up by an interaction damage rule (figure 30),

$$
F_{P P} / N_{P P}+F_{P C} / N_{P C}\left(\text { or } F_{C P} / N_{C P}\right)+F_{C C} / N_{C C}=1 / N_{\text {pred }}
$$

Here $N_{P P}, N_{P C}, N_{C P}$ and $N_{C C}$ are obtained from the four generic life relationships as shown in figure 30 and $F_{P P}=\Delta \varepsilon_{P P} / \Delta \varepsilon_{i n} ; F_{P C}=\Delta \varepsilon_{P C} / \Delta \varepsilon_{i n} ; F_{C P}=\Delta \varepsilon_{C P} / \Delta \varepsilon_{i n}$ and $F_{C C}=$ $\Delta \varepsilon_{c c} / \Delta \varepsilon_{i n}$, where $\Delta \varepsilon_{i n}$ is the total inelastic strain range.

In several high temperature alloys SRP has been found to satisfactorily predict life within a factor of 2 (Halford et al 1972; Hirschberg \& Halford 1976; Hoffeiner et al 1983). Several modifications have been proposed to the SRP approach subsequently. A ductility normalized SRP has been suggested to take into account the effect

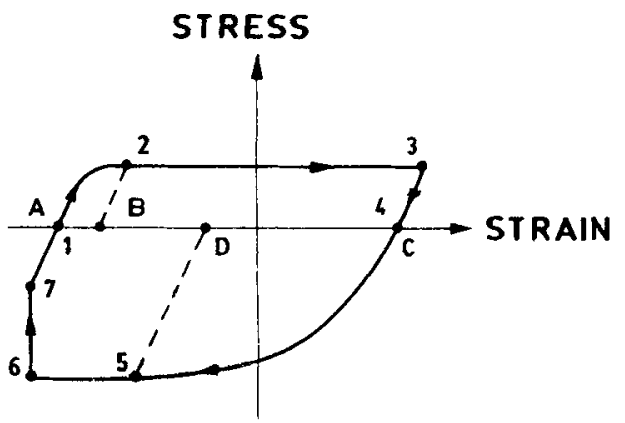

$$
\begin{array}{ll}
\Delta \epsilon_{P P}=A B & \Delta \epsilon_{C C}=D A \\
\Delta \epsilon_{P C}=0 & \Delta \epsilon_{C P}=(B C-D A) \\
\Delta \epsilon_{I N}=\Delta \epsilon_{P P}+\Delta \epsilon_{C C}+\Delta \epsilon_{C P}=A C
\end{array}
$$

Figure 29. Defining partitioned strain range components of complex hysteresis loop (Hirschberg \& Halford 1976). 


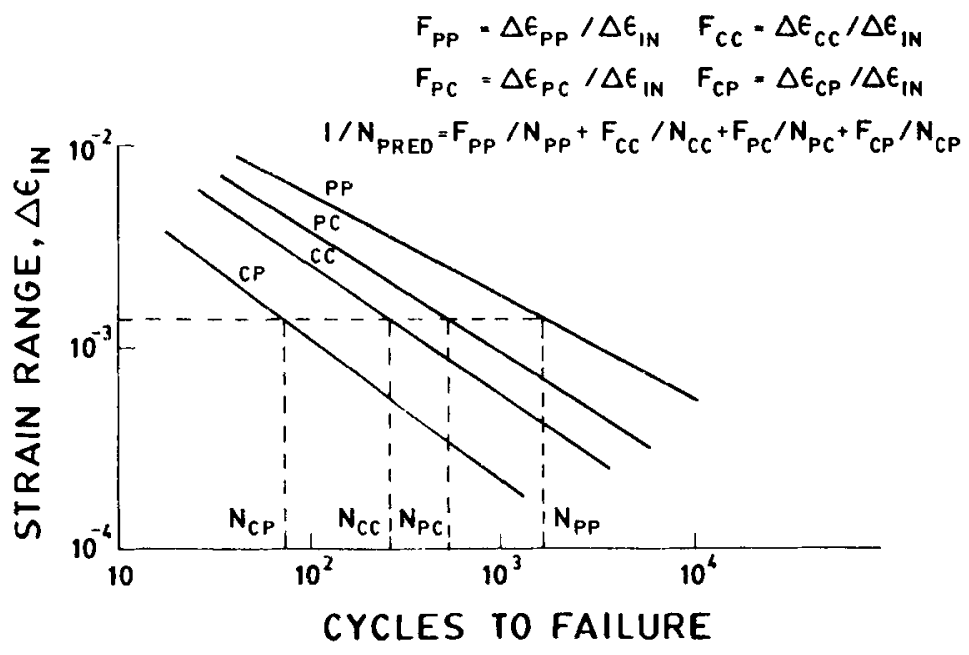

Figure 30. Definition of terms for an interaction damage rule (Hirschberg \& Halford 1976).

of variables like environment, heat to heat variations, degree of cold work, heat treatment, radiation damage and thermal exposure (Halford et al 1977). A total strain range version of the original SRP has been put forth to evaluate creep-fatigue interaction under low strain conditions (Halford \& Saltsman 1983; Saltsman \& Halford 1985), where inelastic strains cannot be determined with sufficient accuracy to make reliable life predictions. Recently, SRP has been modified by Duan et al (1988) to enable life prediction in high strength low ductility alloys. This approach synthesises the energy concept of Ostergren (1976b) and the inelastic strain partitioning of the SRP.

Detailed investigation on the time dependency of strain range partitioning approach for CP cycles has been examined by Kalluri \& Manson (1984). For CP cycle, the time taken for introducing a given amount of creep strain depends on the position and the type (stress or strain) of hold. For example, the creep strain accumulated during stress relaxation in a tensile strain hold test can be obtained within a much shorter time in a corresponding stress hold test. Hence, the time required to complete the hysteresis loop differs, and therefore, suitable modifications to the $\mathrm{CP}$ life relationships incorporating the time parameter has been proposed to take into account various timedependent damaging processes (Kalluri \& Manson 1984).

Some of the advantages of SRP include the following:

(a) SRP can be used to establish upper and lower bounds on life from the most conservative and least conservative of partitioned strain range versus life relationships:

(b) Wave shape effects are treated directly;

(c) Fatigue relationships are relatively temperature insensitive. The effect of temperature is to alter creep and plasticity in a cycle;

(d) Environmental effects are introduced through basic ductility normalized relationship. 
This approach suffers from the following disadvantages.

(a) Accurate knowledge of the cyclic history of service components is required, complex loops become naturally difficult to partition;

(b) Hysteresis loops need to be closed;

(c) Life predictions may be inaccurate in situations where the dominant degrading mechanism is environmental;

(d) If the failure relationships lie close to each other or when there is a cross over between them, choice of a strain range component that causes maximum damage becomes difficult.

\subsection{Hysteresis energy approach}

Ostergren (1976b) has proposed a damage function based on net tensile hysteresis energy for predicting fatigue life under different frequencies and hold time conditions. Further, the mean stress concept is introduced to take into account the detrimental effects of compression holds in some nickel hase superalloys (Leven 1973; Lord \& Coffin 1973; Ostergren 1976b). The tensile hysteresis energy is approximated as $\Delta W_{T}=\sigma_{T} \Delta \varepsilon_{p}$ where $\sigma_{T}$ is the tensile stress range and $\Delta \varepsilon_{p}$ is the plastic strain range. It is then assumed that universality of Coffin-Manson law applies to the hysteresis energy and hence

$$
\sigma_{T} \Delta \varepsilon_{p} N_{f}^{\beta}=\text { constant. }
$$

Here $\sigma_{T}=\sigma_{m}+\Delta \sigma / 2$, where $\sigma_{m}=$ mean stress and $\Delta \sigma$ is the stress range corresponding to a given $\Delta \varepsilon_{p}$. The above equation has been modified for frequency and hold time conditions during which, time-dependent damages become significant as,

$$
\sigma_{T} \Delta \varepsilon_{p} N_{f}^{\beta} \nu^{\beta(k-1)}=\text { constant. }
$$

Frequency is suitably defined depending upon the damaging effects of compression and tension holds. In this way, the beneficial and harmful effects of compression holds could be accounted for.

\subsection{Ductility exhaustion approach}

In the ductility exhaustion approach (Edmunds \& White 1966) it is assumed that the specimen failure occurs when the accumulated creep relaxation strain in a hold time test becomes equal to the monotonic creep ductility of the material. Life predicted using this approach, however, is found to be highly conservative. It was proposed (Priest \& Ellison 1980,1981) that only a fraction of the relaxed strain should be compared with creep ductility. This fraction was defined by a transition strain rate above which matrix deformation dominates and contributes to fatigue damage and below which grain boundary damage accumulates and creep becomes important (figure 31). Here $\Delta \varepsilon_{c}$ corresponds to the creep strain accumulated in a hold cycle and $\Delta \varepsilon_{p}=$ "effective" plastic strain component (i.e. part of the inelastic strain range not associated with the grain boundary damage) and $\Delta \varepsilon_{P P}=$ plastic strain corres- ponding to pure fatigue. Transition strain rates corresponding to the damage processes are obtained frorn deformation mechanism maps typically as shown in figure 32 for $1 \mathrm{Cr}-1 \mathrm{Mo}-\mathrm{V}$ steel, $565^{\circ} \mathrm{C}$, grain size $23 \mu \mathrm{m}$ (Priest \& Ellison 1981). 


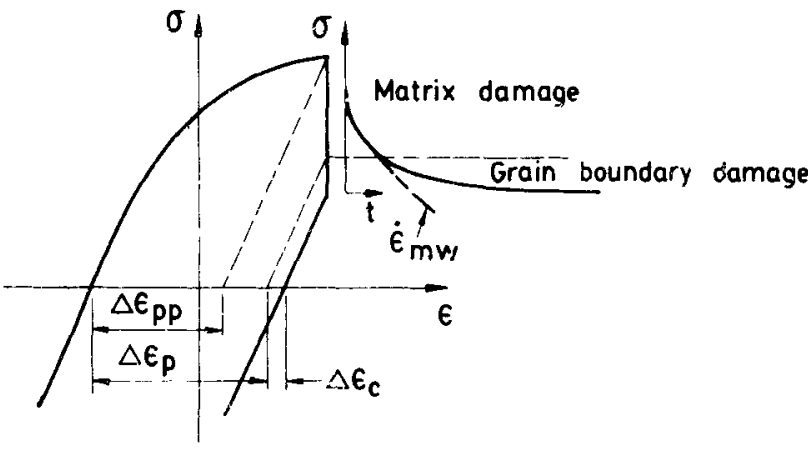

Figure 31. Partitioning of a typical cyclic-hold hysteresis loop (Priest \& Ellison 1981).

In this method, creep and fatigue are considered to be independent damaging processes which compete to cause failure. The one that reaches its critical ductility exhaustion in the least number of cycles dominates the mode of failure. A creep-fatigue loading situation is creep dominated when $N_{c} \Delta \varepsilon_{c}=D_{c}$, where $D_{c}$ is the tensile creep ductility, and $N_{c}$ is the life. Rupture ductility of a material is not a constant but depends on temperature, strain rate, metallurgical variables and state of deformation (i.e., constrained or unconstrained). Fatigue damage dominated life times are similarly expressed by an equation $N_{p} \Delta \varepsilon_{p}=D_{p}$, where $N_{p}=$ fatigue dominated life time and $D_{p}=$ fatigue ductility defined by the strain intercept at one reversal from Coffin-Manson plot. For creep-fatigue interaction, the two mechanisms are summed linearly as

$$
1 / N_{c}+1 / N_{p}=1 / N_{\text {pred }}
$$

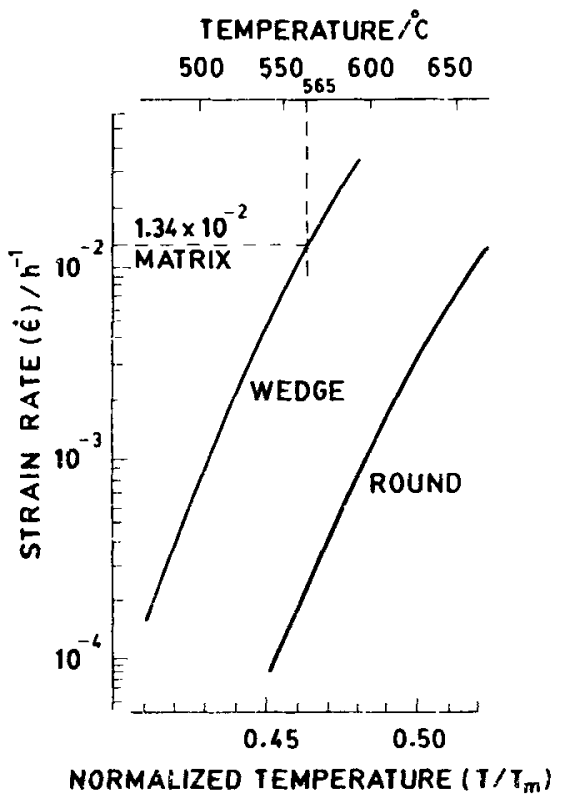

Figure 32. Variation in dominant damage mechanisms with temperature and strain rate $(1 \mathrm{Cr}-\mathrm{Mo}-\mathrm{V}$ stecl; $\mathrm{d}=23 \mu \mathrm{m})$ (Priest \& Ellison 1981). 
Good predictions have been reported by the application of this technique to $1 \mathrm{Cr}-\mathrm{Mo}-\mathrm{V}$ steel data, figure 33 (Priest \& Ellison 1981). This method has been used successfully for predicting creep-fatigue life by a number of investigators for both ferritic and austenitic steels (Miller et al 1982; Priest et al 1983; Tomkins 1983; Wood et al 1988) and also for $17 \mathrm{Cr}-8 \mathrm{Ni}-2 \mathrm{Mo}$ weld metal (Wood et al 1988). Damage healing effects can be accommodated by the ductility exhaustion technique (Priest et al 1983). This method can also be employed for slow-fast cycling conditions (Tomkins 1983).

Ductility exhaustion method has the following limitations.

(a) Severe damaging effects of compressive dwells seen in nickel base alloys are difficult to predict by this method.

(b) Ductility is not a unique material property. Coffin-Manson plots exhibit twoslope behaviour under certain circumstances; determination of fatigue ductility in those situations is uncertain. Variability in creep ductility from heat to heat makes it difficult to select appropriate ductility values for creep damage. Further, tensile creep ductility may not be the appropriate one to use in compression hold conditions.

(c) Determination of transition strain rate in hold tests needs elaborate metallographic investigations.

(d) Deformation mechanism maps used for establishing the damage regime boundaries are only as good as the equations from which they are derived. Semi-empirical nature of the maps casts doubts with respect to their applicability to different sets of data.

\subsection{Damage rate model}

A strain-based approach which takes into account the rate of damage development has been suggested by Majumdar \& Maiya (1976a, 1976b, 1979) and Maiya \& Majumdar

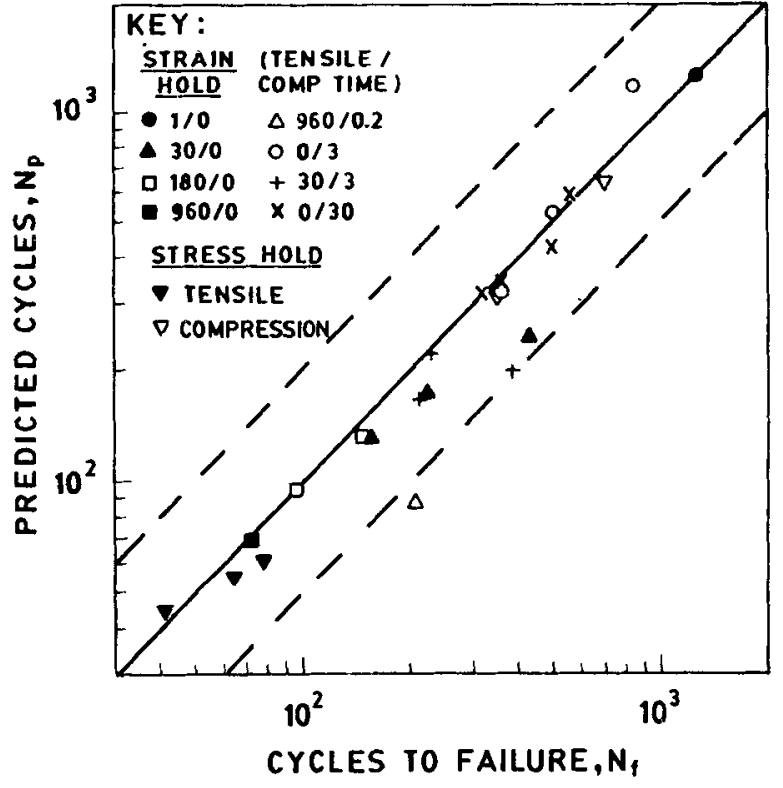

Figure 33. Comparison of observed and predicted lives by ductility exhaustion approach for various cycle shapes (data from Priest \& Ellison 1981). 
(1977). It is assumed that there are two types of damage namely cracks (fatigue) and cavities (creep) in creep-fatigue situation. If the two damage mechanisms are additive, the damage rate is given by the sum of equations:

and

$$
\frac{1}{a} \frac{\mathrm{d} a}{\mathrm{~d} t}= \begin{cases}T\left|\varepsilon_{p}\right|^{m}\left|\dot{\varepsilon}_{p}\right|^{k_{a}} & \text { (for tension), } \\ C\left|\varepsilon_{p}\right|^{m}\left|\dot{\varepsilon}_{p}\right|^{k_{a}} & \text { (for compression), }\end{cases}
$$

$$
\frac{1}{c} \frac{\mathrm{d} c}{\mathrm{~d} t}= \begin{cases}G\left|\varepsilon_{p}\right|^{m}\left|\dot{\varepsilon}_{p}\right|^{k_{c}} & \text { (for tension), } \\ -G\left|\varepsilon_{p}\right|^{m}\left|\dot{\varepsilon}_{p}\right|^{k_{c}} & \text { (for compression). }\end{cases}
$$

Equation (17) describes the crack damage due to fatigue and (18) describes the cavitation damage due to creep. $T, C, G, k_{a}, k_{c}$ and $m$ are material parameters which are functions of temperature, environment and metallurgical state of the material; $\varepsilon_{p}$ and $\dot{\varepsilon}_{p}$ are current absolute values of plastic strain and strain rate respectively, and $a$ and $c$ are the crack size and cavity size respectively at time, $t, T$ and $C$ are included to account for differences in growth rates cccurring in tension and compression. $G$ or $-G$ is used to denote tension or compression. Final failure is calculated as the reciprocal of the sum of crack and cavity damage.

For the cases where the fatigue and creep damages are interactive, crack damage (17) has been modified as,

$$
(1 / a) \mathrm{d} a / \mathrm{d} t=\{T \text { or } C\}\left(1+\alpha \ln c / c_{0}\right)\left|\varepsilon_{p}\right|^{m}\left|\dot{\varepsilon}_{p}\right|^{k_{a}},
$$

and the expression for cavitation damage remains the same.

In the cavity growth formulation, (18), it is assumed that the cavities are widely separated and hence growth occurs independently. Further, the presence of cracks do nut influence the growth of cavities. However, cavities of size greater than $c_{0}$ interact with crack and increase the crack growth rate. This is considered in the interactive damage rule by introducing a term $\left(1+\alpha \ln c / c_{0}\right)$ into (19).

In the interactive darage rule, failure is assumed to occur when the crack length $a$ reaches the size for failure $a_{f}$. If $\alpha=0$, the fatigue crack growth is unaffected by cavities and (19) reverts to continuous cycling. (17).

The interactive damage rate model has been found to satisfactorily predict fatigue lives for several high temperature alloys (Majumdar \& Maiya 1976a). The main advantage of this model is that it takes into account microstructural damage parameters and their evolution with time. Secondly, it incorporates interaction between fatigue and creep damage modes. Strain history of components can be calculated more reliably than their stress history, nuaking this method more usefui to designers. Moreover, the model can also be applied to situations when the stress-strain hysteresis loops are not closed. However, determination of a large number of parameters involved in these equations needs elaborate experimentation. Further, definition of initial crack and cavity sizes needs careful consideration.

\subsection{Tomkins and Wareing's model}

Tomkins \& Wareing (1977) and Wareing et al (1980) have extended the model proposed by Tomkins (1968) for fatigue crack growth to include the influence of cavitation. In Tomkins' model (1968) it is assumed that crack initiation is a negligible 
phase and the entire life is spent for crack propagation. During crack growth, a new crack surface is generated by shear decohesion mechanism at the crack tip. The extent of decohesion is related to the extent of intense crack tip deformation $(D)$ and the applied plastic strain range. In other words, the factors determining the crack growth rate per cycle are the magnitude of the applied stress-strain field, the current crack length and a material strength parameter. Fatigue endurance is determined by the initial crack size, rate of crack growth and the critical crack size.

In this model, the crack propagation rate is expressed as,

where

$$
\mathrm{d} a / \mathrm{d} N=\Delta \varepsilon_{p} D / 2^{1 / 2}
$$

$$
\begin{aligned}
D & =2^{1 / 2}\left[\sec \left(\pi \sigma_{T} / 2 \bar{T}\right)-1\right] a \\
\sigma_{T} & =K^{\prime} \Delta \varepsilon_{p}^{n^{\prime}} ; \\
K^{\prime} & =\text { cyclic strain hardening co-efficient; } \\
n^{\prime} & =\text { cyclic strain hardening exponent; } \\
\bar{T} & =\text { approximately equal to cyclic UTS; } \\
a & =\text { instantaneous crack length; } \\
D & =\text { extent of deformation at the crack tip; } \\
\Delta \varepsilon_{p} & =\text { applied plastic strain range. }
\end{aligned}
$$

For $\sigma_{T} / \bar{T}<0.6$ and a power law for $\sigma_{T}$, integration of (20) gives Coffin-Manson law.

where

$$
\Delta \varepsilon_{p} N_{f}^{\alpha}=\left[\left(8 / \pi^{2}\right)\left(\bar{T} / K^{\prime}\right)^{2} \ln \left(a_{f} / a_{0}\right)\right]^{\alpha},
$$

$$
\begin{aligned}
& \alpha=1 /\left(2 n^{\prime}+1\right) \\
& a_{f}=\text { final crack length; } 2 / 3 \text { of the specimen section, } \\
& a_{0}=\text { initial crack length }(10 \mu \mathrm{m} \text { for ductile materials }) .
\end{aligned}
$$

From (21) it follows that the slope of the fatigue life curve is related only to the slope of cyclic stress strain curve. The position of fatigue curve is dependent on the ratios $\left(\bar{T} / K^{\prime}\right)$ and $\left(a_{f} / a_{0}\right)$. As $\bar{T}$ and $K^{\prime}$ are both strength parameters, variations in strength levels alone will not affect endurance for cycling at a given strain range. As the ratio $a_{f} / a_{0}$ is in the logarithmic form in (21), this must change drastically to effect a significant positional change. The slope of the cyclic stress-strain curve is then the most significant factor affecting endurance.

Applicability of Tomkins' model has been examined for austenitic stainless steels (Wareing 1988), ferritic steels (Wareing 1988; Choudhary et al 1991b) and a magnesium alloy (Wareing 1988). In the case of austenitic stainless steels, a good agreement between predicted and experimental lives has been obtained for various testing and microstructural conditions. However, major differences between the predicted and experimental lives were noticed at low strain ranges (figure 34), where number of cycles required for crack initiation becomes significant. The ability of the crack propagation model, based primarily on stress parameter, to predict fatigue endurance at ambient and elevated temperatures is a consequence of the 


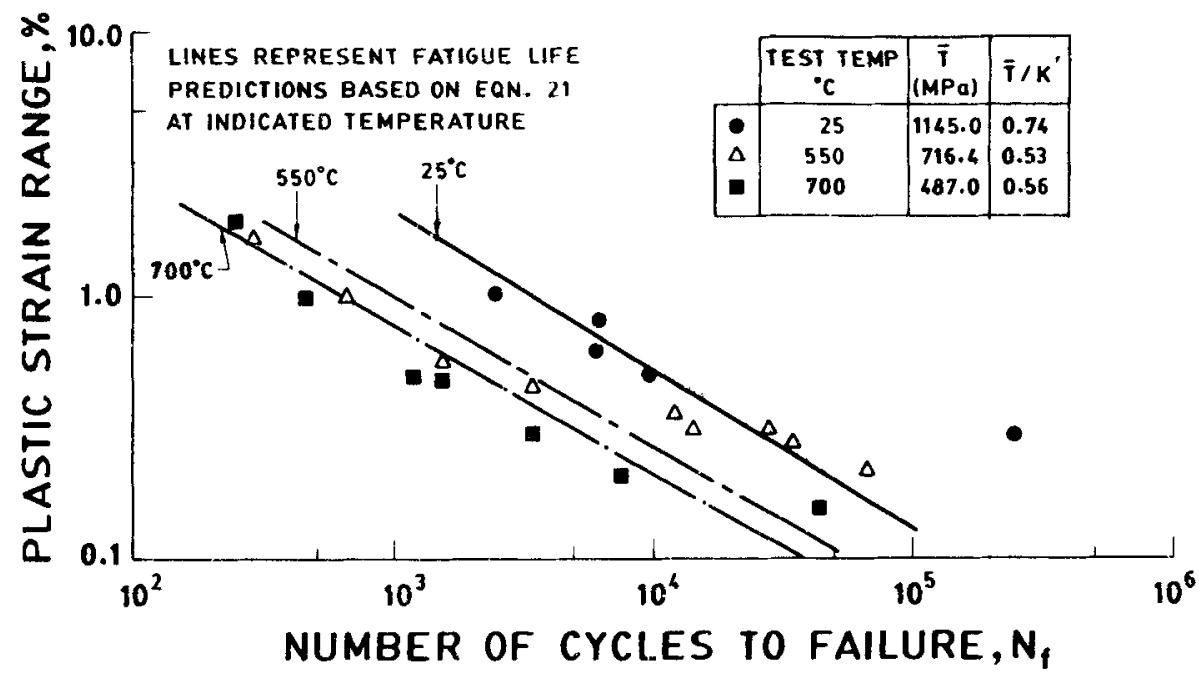

Figure 34. Coffin-Manson plots for type 316 SS at various temperatures (Wareing 1988).

balanced nature of cycle which precludes the formation of creep damage at elevated temperatures.

Crack propagation during creep-fatigue situation occurs in three distinct phases: Phase I is characterised by ductile striations and the growth rate in a tensile hold test is identical to that observed for the same applied strain amplitude without dwell period in the cycle. Phase II which occupies a major portion of the fracture surface occurs very rapidly compared to phase I and follows intergranular path. The reason for the large increase in growth rate is the attainment of cavity linkage at the crack tip. This triggers the unzipping of the cavitated material by the crack tip displacement field. Finally phase III, unstable fracture, occurs in a single cycle. The criterion for the onset of phase $I I$ is given by (1). An approximate solution for $\delta$ in a fully plastic field is giver: by (Tomkins 1975):

$$
\delta / 2=\ln \left(\sec \left(\pi \sigma_{T} / 2 \bar{T}\right)\right)\left[(2 \bar{T} / E)+\left(2 \Delta \hat{s}_{p} /\left(1+n^{\prime}\right)\right)\right] a .
$$

Because phase II is so rapid, the life of a specimen failing by this mechanism is the cycle for initiation and phase I growth, i.e., the number of cycles to attain the critical crack size $a_{f}^{\prime}$, commensurate with the prevailing cavity spacing. For rapid crack initiation, this is obtained by substituting $a_{0}(10 \mu \mathrm{m})$ and $a_{f}^{\prime}$ in Tomkins' model.

Predictions of this model are compared with experimental data for $316 \mathrm{SS}$ at $843 \mathrm{~K}$ for various tensile hold time tests in figure 35. Continuous cycling data are in good agreement with the prediction of (21). For the hold time tests, the data at the highest strains are in line with the prediction ( 1 and 22 ) for a cavity spacing of $1 \mu \mathrm{m}$. With decreasing strain range, the data are more in line with prediction based on spacings of 0.2 and $0.1 \mu \mathrm{m}$. However, at the lowest strain range $(0.15 \%)$, prediction overestimates life data. For strain ranges greater than $0.15 \%$, fracture surfaces were predominantly intergranular with fatigue striations close to the specimen surface, thus confirming the model proposed for crack cavity interaction during creep-fatigue failure. 


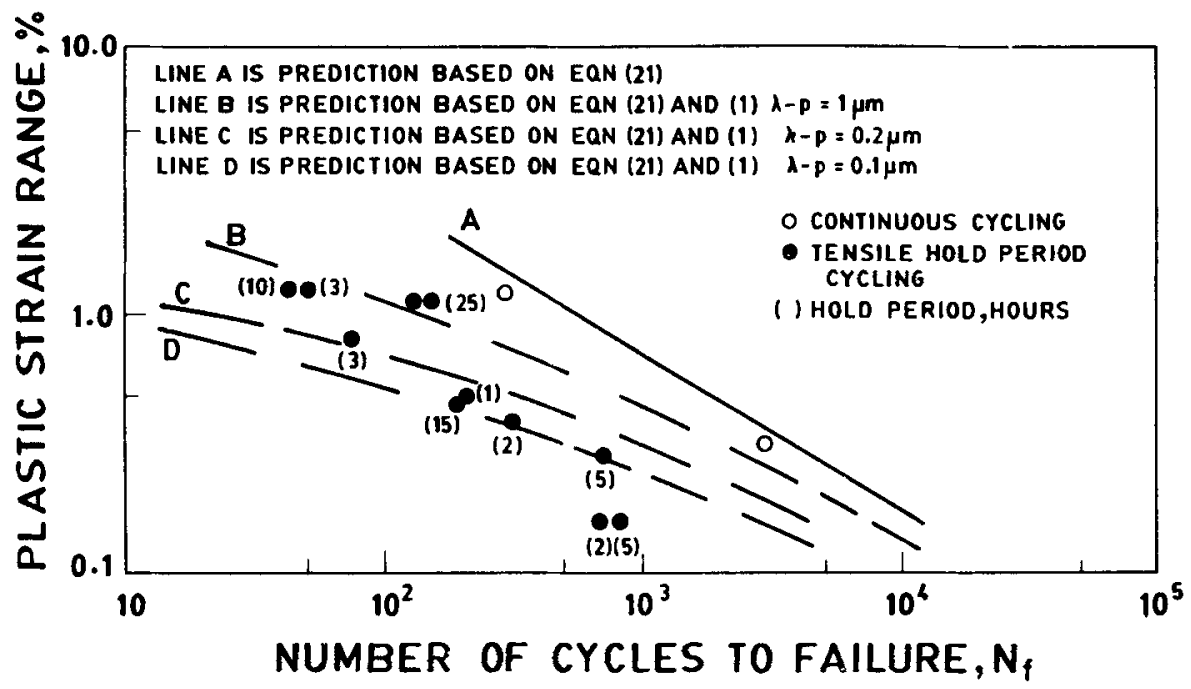

Figure 35. Comparison of predicted and experimental data of fatigue life in type $316 \mathrm{SS}$ tested at $843 \mathrm{~K}$ with various tensile hold periods (Wareing 1988).

\subsection{Cavitation model of Rie et al}

A model has been proposed by Rie et al (1988) which takes into account the nucleation and growth of $r$-type cavities on the grain boundaries under creep-fatigue conditions. Fatigue life is defined by unstable crack advance; this happens if the crack tip opening displacement becomes equal to the spacing of the nucleated intergranular cavities, (1), which leads to unzipping of cavitated material by crack tip displacement field.

Suitable expressions for $\lambda, p$ and $\delta$ have been derived based on physical models of cavity nucleation, their growth and crack-tip opening displacement due to creepfatigue. A cycle-dependent cavity nucleation under cyclic creep and low cycle fatigue conditions with superimposed hold time is considered for evaluating the number of cavities at the grain boundaries perpendicular to load axis. Cavity spacing, $\lambda$ is then determined from cavity denșity. While the nucleation of cavities is governed by deformation of the matrix, cavity growth is controlled by diffusion (Miller et al 1979). The crack-tip opening displacement includes an elastic term plus a contribution due to plastic deformation and thermally activated time-dependent processes (Ilschner 1982). The fatigue life is then estimated using criterion of the critical cavity configuration. The predicted and experimental fatigue lives are compared in figure 36 . The method is capable of predicting lives even for conditions of long hold periods. This model is physically more reasonable compared to Tomkins \& Wareing's (1977), model even though the failure criterion for unstable crack growth is same for both (1). In Tomkins and Wareing's model, arbitrary empirical values are assumed for $(\lambda-p)$ term to get the best fit for the experimental fatigue life, whereas, in the model of Rie et al (1988) suitable mathematical expressions for $\lambda$ and $p$ are derived based on theoretical consideration including contribution to $\delta$ due to creep. 


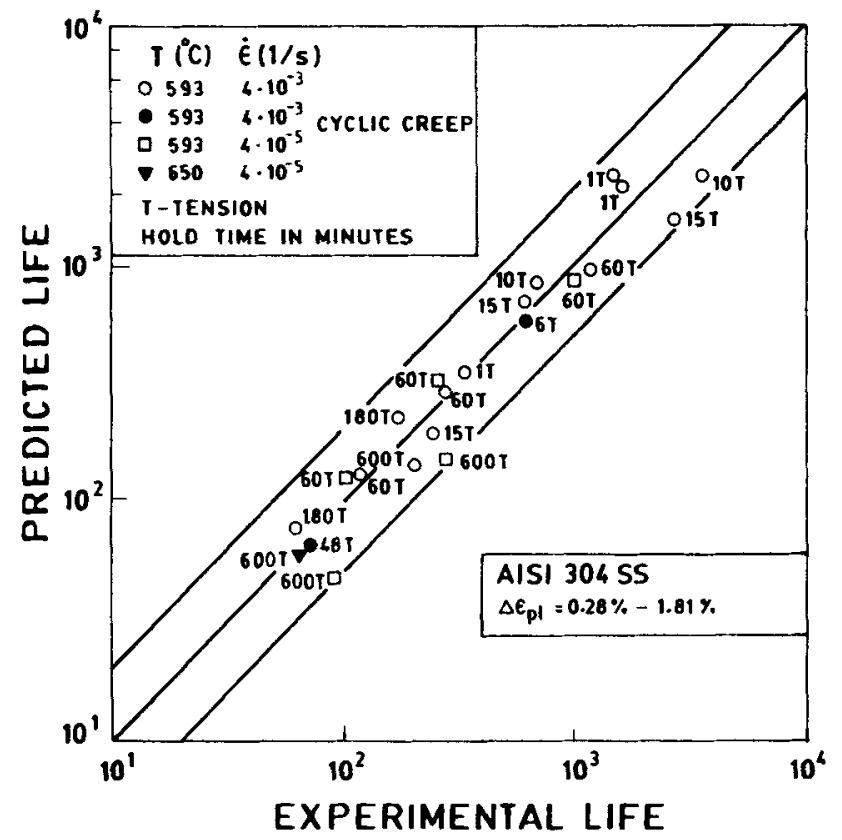

Figure 36. Comparison of experimental life and predicted life following the cavitation model proposed by Rie et al (1988) in AISI type 304 SS.

\section{Concluding remarks}

In this review, the complex nature of high temperature low cycle fatigue phenomenon has been highlighted. It is shown that various time-dependent phenomena like oxidation, dynamic strain ageing and creep interact with cyclic loading to determine life of high temperature components. The importance of a particular time-dependent process depends on the material, its microstructural condition and test parameters like strain range, frequency, position and duration of hold and temperature. Important life prediction techniques for components subjected to high temperature fatigue have been briefly reviewed. The applicability of these approaches is dependent on material and service parameters. A complete understanding of the different processes that occur during time-dependent low cycle fatigue is required before a unified approach applicable to different conditions could be developed.

Oxidation can cause severe degradation in fatigue life influencing both crack initiation and propagation processes. The influence of environment becomes more pronounced with lowering of frequency, decreasing strain amplitude and imposition of hold during fatigue testing. In tests on 304 SS, it was observed that as the frequency was lowered, crack initiation changed from transgranular (induced by slip band) to intergranular mode (induced by oxidation). From comparative tests in air and vacuum environments, it is seen that while life decreases with decrease in frequency in air environment, frequency has little effect in vacuum. Oxidation effects become more important at low strain amplitudes. Depending on the material under consideration, either tensile or compressive holds could be more damaging. This has been attributed to the behaviour of oxide formed during the hold period on subsequent loading. A variety of mechanisms have been identified for oxidation-fatigue interaction that contribute to deterioration in life. 
Dynamic strain ageing (DSA) has been found to exert a significant influence on LCF behaviour at high temperatures. Occurrence of DSA manifests during total straincontrolled fatigue tests in the form of serrations in stress-strain hysteresis loops, increased cyclic work hardening, reduced plastic strain range and increase in response stress with decrease in strain rate or increase in temperature. Further, DSA causes localisation of plastic flow leading to enhanced planarity of slip and widely-spaced slip bands. Impingement of slip bands on grain boundaries causes increased grain boundary decohesion, leading to reduced fatigue life.

Unbalanced slow-fast cycling and tensile hold conditions introduce cavitational damage in addition to fatigue cracking. In creep-fatigue interaction, cyclic loading increases creep cavitation damage and cavitation has been found to enhance fatigue crack initiation and propagation. Rapid crack growth occurs under conditions where fatigue crack can link-up with grain boundary cavities. The susceptibility of a material to creep-fatigue damage is sensitively dependent on the creep ductility of the material. Creep brittle materials are particularly sensitive to interaction damage. While generally tensile holds are more detrimental to life in most of the materials, compressive holds have been found to be deleterious for nickel base alloys.

Several life prediction techniques have been proposed for components under creepfatigue interaction. These range from purely empirical to mechanistic models based on microstructural observations. Best known among these techniques are linear damage summation rule, strain range partitioning, frequency modification approaches and models based on micromechanistic considerations like ductility exhaustion, damage rate and fatigue crack-cavity interaction. To be reliable, the techniques must take into account the physical damage processes occurring during creep-fatigue interaction. The understanding of creep-fatigue interaction behaviour would aid in extrapolation of short term laboratory data to long term service conditions, involving complex loading situations under operating conditions for a wide range of materials. While linear damage rule does not have a mechanistic basis, it is still the best available tool to design engineers, because of its simplicity. Refinements to the linear damage approach could be achieved by replacing creep damage term $t / T_{d}$ by $\varepsilon / \varepsilon_{r}$ where $\varepsilon$ is the accumulated creep strain and $\varepsilon_{r}$ is the appropriate rupture ductility, thereby introducing deformation and fracture into failure criterion. Creep damage term $\left(\Delta \varepsilon_{c} / D_{c}\right)$ of the ductility exhaustion method could also be incorporated in the linear damage rule to predict realistic damage fraction due to creep rather than the term $t / T_{d}$. Fatigue crack-cavitation interaction models appear quite promising as they are based on sound mechanistic considerations. These would be particularly applicable to situations where extensive creep cavitation is encountered.

The authors gratefully acknowledge the collaboration of Dr M Valsan, A Veeramani and G Sasikala in the preparation of this paper.

\section{References}

Abdel-Azim Metwally 1986 Mechanical properties of some high temperature alloys (Alloy $800 \mathrm{H}$ and Alloy 617). Ph D thesis, Cairo University

Abdel-Raouf H, Plumtree A, Topper T H 1973 Effects of temperature and deformation rate on cyclic strength and fracture of low carbon steel. In Cyclic stress-strain behaviour: analysis, experimentation and failure prediction. ASTM STP 519, pp. 28-57 
Antunes V T A, Hancock P 1978 AGARD Conf. Proc. 243

Asada Y, Mitsuhashi S 1980 Creep-fatigue interaction of type 304 stainless steel in air and vacuum. In Int. Conf. Eng. Aspects of Creep (Sheffield: Inst. Mech. Eng.) 1: 199-202

ASME 1992 Boiler and Pressure Vessel Code, Section III, Case N47-14, Class I components in elevated temperature service (New York: ASME)

Basquin O H 1910 The exponential law of endurance tests. Proc. Am. Soc. Test. Mater. 10: 625-630

Berling J T, Conway J B 1970 Effect of hold time on the low cycle fatigue resistance of 304 stainless steel at $1200^{\circ} \mathrm{F}$. Proc. I st Int. Conf. Pressure Vessel Tech. Part II (New York: ASME) pp. 1233-1246

Bhanu Sankara Rao K 1989 Influence of metallurgical variables on low cycle fatigue behaviour of type 304 stainless steel. Ph D thesis, University of Madras

Bhanu Sankara Rao K, Mannan S L, Rodriguez P, Schuster H, Schiffers H, Meurer H P, Nickel H 1988 Proc. Indo-German Seminar on Trends and Techniques in Modern Materials Research, IGCAR-Kalpakkam, Report No. 99c, pp. 81-92

Bhanu Sankara Rao K, Meurer H P. Schuster H 1988 Creep-fatigue interaction of Inconel 617 at 950 $\mathrm{C}$ in simulated nuclear reactor helium. Mater. Sci. Eng. A104: 37-51

Bhanu Sankara Rao K, Sandhya R, Mannan S L 1993 Creep-fatigue interaction behaviour of type 308 stainless steel weld metal and type 304 stainless steel base metal. Int. J. Fatigue 15: 221 - 229

Bhanu Sankara Rao K, Schiffers H, Schuster H 1986c (Unpublished) Research Work (KFAJulich, Germany)

Bhanu Sankara Rao K. Valsan M, Sandhya R, Mannan S L 1994 (Unpublished) Research Work, Kalpakkam

Bhanu Sankara Rao K, Valsan M, Sandhya R, Mannan S L, Rodriguez P 1986a Grain size dependence of creep-fatigue-environment interaction in AISI 304 stainless steel. Int. Conf. on Creep (Tokyo: JSME, Inst. Mech Eng. ASME, ASTM) pp. 77-83

Bhanu Sankara Rao K, Valsan M, Sandhya R, Mannan S L, Rodriguez P 1986b Dynamic strain ageing effects in low cycle fatigue. High Temp. Mater. Proc. 7: 171- 177

Bhanu Sankara Rao K, Valsan M, Sandhya R, Mannan S L, Rodriguez P 1989 Grain size dependence of dynamic strain ageing during low cycle fatigue in type 304 stainless steel, 7 th Int. Conf. Fracture, Adv. in Fracture Research, (eds) K Salama, K Ravi Chandar, D M R Taplin, P Rama Rao (London: Pergamon) 2: $1037 \cdots 1044$

Bhanu Sankara Rao K, Valsan M. Sandhya R, Mannan S L, Rodriguez P 1990 Manifestations of dynamic strain ageing during low cycle fatigue of type 304 stainless steel. Metall. Mater. Proc. 2: $17-36$

Bhanu Sankara Rao K. Valsan M, Sandhya R. Mannan S L, Rodriguez P 1991 Synergistic interactions during high temperature fatigue of type 304 stainless steel - grain size dependence. Trans. Indian Inst. Met. 44: 255-270

Booker M K, Majumdar S 1982 Specialists Meeting on "Structural material data" held at the Power Reactor and Nuclear Fuel Development Corporation, Tokyo, Japan

Bressers J 1985 Fatigue and microstructure. Proc. Int. Conf. on High Temperature Alloys and their Exploitable Potential (eds) J B Marriott. M Merz, J Nihoul, J Ward (London: Elsevier) pp. 385-410

Bressers J, De Cat R, Fenske E 1983 Crack initiation and growth in high temperature low cycle fatigue. Cost 501, III Final Report EVR 8808 EN

Bressers J, Roth M 1983 The effect of time-dependent processes in high temperature low cycle fatigue endurance of PM Astroloy. Proc' of ASME Int. Conf. on Advances in Life Prediction Methods (eds) D A Woodford. J R Whitehead (New York: ASME) pp. 85-92

Bressers J, Verhegghee B 1981 Res. Mech. Lett. 1: 55

Bricknell R H. Woodford D A 1981 The embrittlement of nickel following high temperature air exposure. Metall. Trans. A12: 425433

Brinkman C R 1985 High temperature time-dependent fatigue behaviour of several engineering structural alloys. Int. Metall. Rev. 30: 235258

Brinkman C R, Korth G E, Beeston J M 1974 Comparison of the strain-controlled low cycle fatigue behaviour of stainless type 304/308 weld and base metal. Int. Conf. on Creep and Fatigue in Elevated Temperature Applications (Sheffield: Inst. Mech. Eng) paper C218-73, pp. 218·1-218.11

Brinkman C R, Korth G E. Hobbings R R 1972 Estimates of creep-fatigue interaction in irradiated and unirradiated austenitic stainless steels. Nucl. Technol. 16: 297-307 
Challenger K D, Miller A K, Brinkman C R 1981 An explanation for the effects of hold periods on the elevated temperature fatigue behaviour of $2 \cdot 25 \mathrm{C}_{\mathbf{r}}-1$ Mo steel. Trans. ASME, J. Eng. Mater. Technol. 103: 7-14

Choudhary B K, Bhanu Sankara Rao K, Mannan S L 1991a High temperature low cycle fatigue properties of a thick-section $9 \mathrm{wt} . \% \mathrm{Cr}-1 \mathrm{wt} . \% \mathrm{Mo}$ ferritic steel forging. Mater. Sci. Eng. A148: 267-278

Choudhary B K, Bhanu Sankara Rao K, Mannan S L 1991 b Application of 9 Cr -1 Mo steel low cycle fatigue data in the design of fast reactor steam generator thick components. Proc. Int. Symp. on Fatigue and Fracture in Steel and Concrete Struct. (eds) A G Madhava Rao, T V S R Appa Rao (New Delhi: Oxford \& IBH) 2: 883-894

Coffin L F 1954 A study of the effects of cyclic thermal stresses on a ductile metal. Trans. Am. Soc. Mech. Eng. 76: 931-950

Coffin L F 1963 Trans. Am. Soc. Mech. Eng. 56: 339

Coffin L F 1969 Predictive parameters and their application to high temperature, low cycle fatigue fracture. Proc. of 2nd Int. Conf. on Fracture. (ed.) P L Pratt (London: Chapman and Hall) pp. 643-654

Coffin L F 1971 The effect of frequency on the cyclic strain and low cycle fatigue behaviour of cast Udimet 500 at elevated temperatures. Metall. Trans. 2: 3105-3113

Coffin L F 1972a The effect of high vacuum on the low cycle fatigue law. Metall. Trans. 3: $1777-1788$

Coffin L F Jr. 1972b Corrosion fatigue. Proc. Int. Conf. on Fatigue Chemistry. Mechanics and Microstructure, NACE-2, Houston, Texas (National Association of Corrosion Engineers) pp. 590-600

Coffin L F 1973a Fatigue at high temperature. Fatigue at elevated temperature (eds) A E Carden, A J McEvily, C H Wells ASTM STP 520, pp. 5-34

Coffin L F 1973b Proc. Int. Conf. Fatigue 3 (Munich) p. 441

Coffin L F 1976 The concept of frequency separation in life prediction for time-dependent fatigue. Symp. on Creep-Fatigue Interaction. ASME-MPC-3, pp. 349-363

Coffin L F 1977 The concept of frequency separation in life prediction for time-dependent fatigue. General Electric, Report No. 76 CRD269

Coffin L F 1979 Proc. DVC Symp. of Low Cycle Fatigue Strength and Elasto-plastic behaviour of materials Stuttgart (eds) K T Rie, E Hamback (Deutscher Verband for material prufing) pp. 73-82

Conway J B 1968 General electric nuclear material and propulsion operation. Report No. 1004, Cincinnati, Ohio

Conway J B, Stenz R H. Berling J T 1975 Fatigue, tensile and relaxation behaviour of stainless steels. TID-26135, US Atomic Energy Commission Report

Cook R H, Skelton R P 1979 Int. Metall. Rev. 19: 199

Cottrell A H 1953 Philos. Mag. 44: 829

Duan Z, He J, Ning Y, Dong Z 1988 Strain energy partitioning approach and its application to low cycle fatigue life prediction for some heat resistant alloys. In Low cycle fatigue (eds) H D Solomon, G R Halford, L R Kaisand, B N Leis ASTM STP 942, pp. 1133-1143

Duquette D J 1979 A mechanistic understanding of the effects of environment on fatigue crack initiation and propagation. Proc. Int. Conf. on Environment Sensitive Fracture of Engineering Materials (ed.) Z A Foroulis (AIME) pp. $521-537$

Dyson B F 1982 An analysis of carbon/oxygen gas bubble formation in some nickel alloys. Acta Metall. 30: 1639-1646

Eckel J F 1951 The influence of frequency on the repeated bending life of acid lead. Proc. Am. Soc. Test. Mater. 51: 745-760

Edmunds H G, White D J 1966 Observations of the effect of creep relaxation on high strain fatigue. J. Mech. Eng. Sci. 8: 310-321

Ellison E G, Patterson A T F 1976 Creep-fatigue interaction in a $1 \mathrm{Cr}-\mathrm{Mo}-\mathrm{V}$ steel. Proc. Inst. Mech. Eng. 190: 321-350

Ericsson T 1979 Can. Metall. Q.18: 177

Essman U, Mughrabi H 1979 Annhilation of dislocations during tensile and cyclic deformation and limits of dislocation densities. Philos. Mag. A40: 731-756

Floreen S, Raj R 1985 Environmental effects in nickel base alloys. In Flow and fracture at elevated temperatures (ed.) R Rishi (Metals Park, OH: ASM) chap. 12 pp. $383-405$ 
Frandson J O, Paton N E. Marcus H L 1974 The influence of gaseous environment on fatigue crack growth in a nickel- copper alloy. Metall. Trans. A5: 1665-1661

Fujita F E 1958 Dislocation theory of fracture of crystals. Acta Metall. 6: 543-551

Gell M, Leverant G R 1973 Mechanisms of high temperature fatigue. In Fatigue at elevated temperatures (eds) A E Carden, A J McEvily, C H Wells ASTM STP 520, pp. 37-67

Halford G R, Hirschberg M H. Manson S S 1972 Temperature effects on the strainrange partitioning approach for creep-fatigue analysis. NASA TM X-68023

Halford G R, Saltsman J F 1983 Strainrange partitioning a total strain range version. NASA TM-83023

Halford G R, Saltsman J F, Hirschberg M H 1977 Ductility normalized strainrange partitioning life relations for creep-fatigue life predictions. NASA TM-73737

Hayes R W, Hayes W C 1984 A proposed model for the disappearance of serrated flow in two Fe-alloys. Acta Metall. 32: 259-267

Hirakawa K. Tokiwasa K. Toyama K 1978 J. Soc. Mater. Sci. Jpn. 27: 948

Hirschberg M H. Halford G R 1976, Use of strainrange partitioning to predict high temperature, low cycle fatigue life NASA TN D-8072

Hoffelner W, Melton K N, Wutbrich C 1983 On life-time prediction with the strainrange partitioning method. Fatigue Eng. Mater. Struct. 6: 77. 87

Ilschner B 1982 Mechanical and thermal hehariour of metallic materials (Bologna: Soc. Ital. Fis.) p. 188

James L A. Knecht R L. 1975 Metall. Trans. A6: 109

Jianting G, Ranuci D. Picco E. Strocchi P M 1984 Effect of environment on the low cycle fatigue behaviour of cast nickel base superalloy IN738LC. Int. J. Fatigue 6: 95.99

Johnson E W, Johnson H H 1965 Trans. Metall. Soc. AIME 233: 1332

Kalluri S, Manson S S 1984 Time dependency of strainrange partitioning life relationships. NASA Contractor Report-174946

Kanazawa K 1978 Trans. Nat. Res. Inst. Met. 20: 321

Kanazawa K, Yamaguchi K, Nishijima S 1988 Mapping of low cycle fatigue mechanisms at elevated tempertures for an austenitic stainless steel. Low $C_{y c l e}$ Fatigue (eds) H D Solomon. G R Halford, L R Kaisand, B N Leis ASTM STP 942, pp. 519-530

Kanazawa K. Yoshida S 1975 Effect of temperature and strain rate on the high temperature low cycle fatigue behaviour of austenitic stainless steels. In Creep and fatigue in elevated temperature applications (London: Inst. Mech. Eng.) 1: pp. 226 I- 226-10

Kempf B, Bothe K, Gerold V 1987 Damage mechanisms under creep-fatigue conditions in Alloy 800 H. In Proc. 2nd Int. Conf. on Elasto-Plastic Behariour of Materials. (ed.) K T Rie (New York: Elsevier) pp. $271-276$

Kubin L. P. Estrin Y 1990 Evolution of dislocation densities and the critical conditions for the Portevin - Le Chatelier effect. Acta Metall. 38: 697. 708

Leven M M 1973 Interaction of creep and fatigue for a rotor steel. Exp. Mech. 13: 353-372

Lloyd G J, Wareing J 1981 Life-prediction methods for combined creep-fatigue endurance. Metall. Technol. 8: $297 \cdot 304$

Lord D C, Coffin L F 1973 Low cycle fatigue hold time behaviour of cast Rene80. Metall. Trans. 4: $1647-1654$

Maiya PS, Majumdar S 1977 Elevated temperature low cycle fatigue behaviour of different heats of type 304 stainless steel. Metall. Trans. A8: $1651 \quad 1660$

Majumdar S, Maiya P S 1976a A damage equation for creep-fatigue interaction. In ASME MPC Symp. on Creep-Fatigue Interaction, MPC-3 (New York: ASME) pp. 323-335

Majumdar S. Maiya P S 1976b Proc. 2nd Int. Conf. on Mechanical Behaviour of Materials (Metals Park, OH: ASM) p. 924

Majumdar S, Maiya P S 1979 Creep fatigue interaction in an austenitic stainless steel. Can. Metall. Q. 18:57.64

Mannan S L 1981 Influence of grain size on flow and fracture in AISI type 316 stainless steel. $\mathrm{Ph} \mathrm{D}$ thesis, Indian Institute of Science, Bangalore

Mannan S L 1993 Role of dynamic strain ageing in low cycle fatigue. Bull. Mater. Sci. 16: $561-582$

Manson S S 1954 Behaviour of materials under conditions of thermal stresses. Nat. Adv. Comm. Aero, Technical Note 2933

Manson S S 1965 Fatigue: A complex subject - some simple approximations. Exp. Mech. 5: 157-190 
Manson S S, Halford G R 1967 Proc. of Int. Conf. on Thermal and High Strain Fatigue (London: Met. Metall. Trust) p. 154

Manson S S, Halford G R 1968 Truns. Am. Soc. Metall. 61: 94

Manson S S, Halford G R, Hirschberg M H 1971 Creep-fatigue analysis by strain-range partitioning. NASA TM X-67838

Manson S S, Halford G R, Oldrieve R E 1984 Report NASA, TM-83473, Lewis Research Center, Cleveland. $\mathrm{OH}$

Marriott D L 1992 Current trends in high temperature design. Int. J. Pressure Vessels Piping 50: 13-35

Marshall P 1983 Fatigue at high temperature (ed.) R P Skelton (London: Elsevier) p. 259

McCormick P G 1972 A model for the Portevin-Le Chatelier effect in substitutional alloys. Acta Metall. 20: 351--354

McMahon C J, Coffin L F 1970 Mechanisms of damage and fracture in high temperature low cycle fatigue of a cast nickel base superalloy. Metall. Trans. 1: 3443-3450

Meurer H P, Breitling H, Grosser E D 1984 Creep-fatigue evaluation of austenitic stainless steel for SNR 300 - present status and future efforts. Nucl. Eng. Design 83: 355-366

Miller D A, Hamm C D, Philips J L 1982 A mechanistic approach to the prediction of creep-dominated failure during simultanęous creep-fatigue. Mater. Sci. Eng. 53: 233-244

Miller D A, Mohamed F A, Langdon T G 1979 An analysis of cavitation failure incorporating cavity nucleation with strain. Mater. Sci. Eng. 40: 159-166

Miller D A, Priest R H, Ellison E G 1984 A review of material response and life prediction techniques under fatigue-creep loading conditions. High Temp. Mater. Proc. 6: $155-194$

Miner M A $1945 J$. Appl. Mech. A12: 159

Mulford R A, Kocks U F 1979 New observation on the mechanisms of dynamic strain ageing and jerky flow. Acta Metall. 27: 1125-1134

Nazmy M Y 1983a High temperature low cycle fatigue of IN738 and application of strain range partitioning. Metall. Trans. A14: 449--461

Nazmy M Y 1983b Effect of multiple crack propagation on the high temperature low cycle fatigue of a cast nickel base alloy. Scr. Metall. 17: 491-494

Nich T G, Nix W D 1981 Embrittlement of $\mathrm{Cu}$ due to segregation of oxygen to grain boundaries. Metall. Trans. A12: 893-901

Ostergren W J 1976a Correlation of hold time effects in elevated temperature LCF using a frequency modified damage function. Symp. on 'Creep-Fatigue Interaction(ed.) R M Curran (New York: ASME-MPC) pp. 179-202

Ostergren W J 1976b A damage function and associated failure equations for predicting hold time and frequency effects in elevated temperature low cycle fatigue. J. Test. Eval. 4: 327-339

Plumbridge W J, Ellison E G 1987 Low cycle fatigue behaviour of superalloy blade materials at elevated temperature. Mater. Sci. Technol. 3: 706-715

Priest R H, Beauchamp D J, Ellison E G 1983 Damage during creep-fatigue. In Proc. Conf. Advances in Life Prediction Methods (Schenectady, NY: Am. Soc. Metall.) pp. 115-121

Priest R H, Ellison E G 1980 Estimation of cyclic creep damage by strain and strain rate considerations. In Proc. Int. Conf. on Eng. aspects of creep (Sheffield: Inst. Mech. Eng.) pp. 185-192

Priest R H, Ellison E G 1981 A combined deformation map - ductility exhaustion approach to creep-fatigue analysis. Mater. Sci. Eng. 49: 7-17

Quesnel D J, Tsou J C 1983 A quantitative approach to cell shuttling model. Mater. Sci. Eng. 59: 91-98

Raj R (ed.) 1985 Mechanisms of creep-fatigue interaction. In Flow and fracture at elevated temperatures (Metals Park, OH: ASM) pp. 215-249

Reger M, Remy L 1986 High temperature fatigue. Journees, Internationales de Printemps, Commission de Fatigue, SFM, Paris

Reuchet J, Remy L 1983 High temperature LCF of MAR-M 509 superalloy - I: The influence of temperature on the LCF behaviour from 20 to $1100^{\circ} \mathrm{C}$. Mater. Sci. Eng. 58: 19-32

Rie K T, Schmidt R M, Ilschner B, Nam S W 1988 A model for predicting low cycle fatigue life under creep-fatigue interaction. Low cycle fatigue (eds) H D Solomon, G R Halford, L R Kaisand, B N Leis ASTM STP 942, pp. 313-328

Robinson E L. 1952 Trans. Am. Soc. Mech. Eng. 74: 777 
Rodriguez P 1984 Serrated plastic flow. Bull. Mater. Sci. 6: 653-663

Rodriguez P 1993 Mechanistic approach to low cycle fatigue life prediction. Prof. T Ramachandran Lecture Series 1993 KREC, Suratkal

Rodriguez P. Bhanu Sankara Rao K 1993 Nucleation and growth of cracks and cavities under creep-fatigue interaction. Prog. Mater. Sci. 37: 403-480

Rodriguez P. Mannan S L, Bhanu Sankara Rao K 1989 Life prediction methods for creep fatigue conditions. Trans. Indian Inst. Met. 42: S25-S43

Saltsman J F, Halford G R 1985 An update of the total-strain version of SRP, NASA TP-2499

Sandhya R, Bhanu Sankara Rao K, Mannan S L 1989 Low cycle fatigue and creep-fatigue interaction of Bainitic $2 \cdot 25 \mathrm{Cr}-1 \mathrm{Mo}$ steel. Trans. Indian Inst. Met. 42: S217-S227

Scarlin R B 1977 Effects of loading frequency and environment on high temperature fatigue crack growth in nickel base alloys, ICF-4 (ed.) D M R Taplin (New York: Pergamon) 1: $849 \cdots 857$

Schmitt R. Scheibe W, Anderko K 1979 Creep-fatigue interaction on 1.4948 austenitic stainless steel, including irradiation effects. Proc. SMiRT-5 Berlin, Paper No. L 12/7

Shen H, Podlaseck S E, Kramer K I 1966 Effect of vacuum on the fatigue life of aluminium. Acta Metall. 14: $341-346$

Sidey D, Coffin L F Jr 1979 Low cycle fatigue damage mechanisms at high temperature. In Proc. Symp. Fatigue mechanismṣ (ed.) J T Fong ASTM STP 675, pp. 528-568

Skelton R P 1978 Environmental crack growth in $0.5 \mathrm{Cr}_{\mathrm{r}}-\mathrm{Mo}-\mathrm{V}$ steel during isothermal high strain fatigue and temperature cycling. Mater. Sci. Eng. 35: 287-298

Sleeswyk A W 1958 Slow strain hardening of ingot iron. Acta Metall. 6: 598-603

Smith H H, Shahinian P, Achter M R 1969 Trans. Metall. Soc. AIME 245: 947

Solomon H D, Coffin L F 1973 Effects of frequency and environment on fatigue crack growth in A286 at $1100^{\circ} \mathrm{F}$. In Fatigue at elevated temperatures ASTM STP 520, pp. 112-122

Srinivasan V S, Sandhya R, Bhanu Sankara Rao K, Mannan S L, Raghavan K S 1991 Effects of temperature on the low cycle fatigue behaviour of nitrogen alloyed type 316L stainless steel. Int. J. Fatigue 13: 471

Swindeman R W, Strizak J P 1982 ORNL TN-8392, Oak Ridge, TN

Taplin D M R, Tang N Y, Liepholz H H E 1984 On fatigue-creep-environment interaction and the feasibility of fatigue maps. Proc. 6th Int. Conf. on Fracture. Advances in Fracture Research (eds) S R Valluri, D M R Taplin, P Rama Rao, J F Knott. R Dubey, vol 1: pp. 127-142

Taplin D M R, Topper T H, Tang N Y 1983 Proc. IC F Int. Symp. on Fracture Mechanics, Beijing

Teranishi H. McEvily A J 1980 On fatigue crack initiation and propagation at elevated temperature. Proc. of 5 th Int. Conf. on Fracture, ICF5, Adv. Fracture Research (ed.) O Francois (Cannes, France: Pergamon) 5: 2439 - 2447

Thompson N. Wadsworth M J, Louat N 1955 The origin of fatigue fracture in copper. Philos. Mag. 1: 113-126

Tomkins B 1968 Fatigue crack propagation - An analysis. Philos. Mag. 18: 1041-1066

Tomkins B 1975 The development of fatigue crack propagation models for engineering applications at elevated temperatures. Trans ASME, J. Eng. Mater. Technol. 97: 289-297

Tomkins B 1983 Life prediction at elevated temperatures. Trans ASME. J. Pressure Vessel Technol. 105: 269 272

Tomkins B, Wareing J 1977 Elevated temperature fatigue interaction in engineering materials. Metall. Sci. 11: 414-424

Tsuzaki K, Hori T, Maki T, Tanura I 1983 Dynamic strain ageing during during fatigue deformation in type 304 austenitic stainless steel. Mater. Sci. Eng. 61: 247-260

Valsan M 1991 Some aspects of deformation and fracture in low cycle fatigue of a Nimonic PE-16 Superalloy. Ph D thesis, Indian Institute of Science, Bangalore

Valsan M, Choudhary B K, Bhanu Sankara Rao K, Mannan S L, Rodriguez P 1988 Internal Report MDD/71·4/88/01, Kalpakkam

Valsan M, Parameswaran P, Bhanu Sankara Rao K, Vijayalakshmi M, Mannan S L, Shastry D H 1992 High temperature low cycle fatigue behaviour of a NIMONIC PE-16 superalloy Correlation with deformation and fracture. Metall. Trans. A23: 1751-1761

Valsan M. Sastry D H, Bhanu Sankara Rao K, Mannan S L, 1994 Effect of strain rate on the high temperature low cycle fatigue properties of a Nimonic PE-16 Superalloy. Metall. Mater. Trans. A25: $159-171$ 
Van den Beukel A, Kocks U F 1982 The strain dependence of static and dynamic strain ageing. Acta Metall. 30: 1027-1041

Venkadesan S 1991 Development and characterisation of the tensile deformation behaviour of a titanium modified austenitic stainless steel. Ph D thesis, Indian Institute of Technology, Madras

Viswanathan R 1989 Damage mechanisms and life assessment of high temperature components (Metals Park, OH: ASM) chap. 4, pp. 111-182

Wareing J 1975 Fatigue crack growth in a type 316 stainless steel and a $20 \mathrm{pct} \mathrm{Cr} / 25 \mathrm{pct} \mathrm{Ni} / \mathrm{Nb}$ stainless steel at elevated temperatures. Metall. Trans. A6: 1367-1377

Wareing J 1977 Creep-fatigue interaction in austenitic stainless steels. Metall. Trans. A8: $711-721$

Wareing J 1981 Creep-fatigue behaviour of four casts of type 316 stainless steel. Fatigue Eng. Mater. Struct. 4: 131-145

Wareing J 1988 Influence of material microstructure on low cycle fatigue failure, with particular reference to austenitic steel. In Low cycle fatigue (eds) H D Solomon, G R Halford, L R Kaisand and B N Leis ASTM STP 942, pp. 711-727

Wareing J, Vaughan H G, Tomkins B 1980 Mechanisms of elevated temperature fatigue and failure in type 316 stainless steel. In Creep-Fatigue-Environment Interaction Proc. TMSAIME Symp. Fall Meeting (eds) R M Pelloux, N S Stoloff pp. 129-150

Wells C H, Sullivan C P 1969 Interactions between creep and low cycle fatigue in Udimet 700 at $1400^{\circ} \mathrm{F}$. In Fatigue at high temperature, ASTM STP 459, pp. 59-74

Wilson D V, Tromans J K 1970 Effects of strain ageing on fatigue damage in low carbon steel. Acta Metall. 18: 1197-1208

Wood D S, Baldwin A B, Williamson K 1979 The creep/fatigue behaviour of $9 \mathrm{Cr}$ steel at $525^{\circ} \mathrm{C}$. Proc. IAEA Meet on 'Time and Load Dependent Degradation of Pressure Boundary Materials', Report IWG-R R PC-79/2 (Innsbruck), pp. 88-101

Wood D S, Wynn J, Austin C, Green J G 1988 A ductility exhaustion evaluation of some long term creep/fatigue tests on austenitic steel. Fatigue Fracture Eng. Mater. Struct. 11: 371-381

Yamaguchi K, Kanazawa K, Yoshida S 1978 Crack propagation in low cycle fatigue of type 316 stainless steel at temperatures below $600^{\circ} \mathrm{C}$ observed by scanning electron microscopy. Mater. Sci. Eng. 33: 175-181

Yoo M H, Trinkaus H 1983 Crack and cavity nucleation at interfaces during creep. Metall. Trans. A14: 547-593 